\title{
Structural Characteristics of Convective Systems over South America Related to Cold-Frontal Incursions
}

\author{
JOSE RICARDO SIQUEIRA
}

Centro de Previsão de Tempo e Estudos Climáticos, Instituto Nacional de Pesquisas Espaciais, Säo José dos Campos, Brazil

\author{
WiLliam B. Rossow
}

NASA Goddard Institute for Space Studies, New York, New York

\section{Luiz Augusto Toledo Machado}

Centro de Previsão de Tempo é Estudos, Climáticos, Institutó Nacional de Pesquisas Espaciais, Säo José dos Campos, Brazil

\section{Cindy Pearl}

SGT, Inc., and NASA Goddard Institute for Space Studies, New York, New York

(Manuscript received 18 December 2003, in final form 15 September 2004)

\begin{abstract}
ABSTRÁCT
International Satellite Cloud Climatology Project (ISCCP DX) and microwave sensor data collected by the Tropical Rainfall Measuring Mission (TRMM) are used to identify and describe structural characteristics of convective systems (CSs) over continental South America (SA) related to cold-frontal incursions in a 3-yr period. An austral wet-season climatology for CS events of the three most important types of front-tropical convection interaction is built by applying latitude-time diagrams and a cloud-tracking method to DX data. Type 1 is characterized by the penetration of a cold front over subtropical SA that interacts with convection and moves with it into lower tropical latitudes. Type 2 refers to Amazon convection and its enhancement in a quasi-stationary northwest-southeast-oriented band extending from the Amazon to subtropical SA along with the passage of a cold front in the subtropics and characterizes the synoptic formation of the South Atlantic convergence zone. A quasi-stationary cold front over subtropical SA that has only weak interaction with tropical convection corresponds to type 3.

Results show that the three types of front-tropical convection interaction strongly modulate deep convection over SA, producing mesoscale CSs with significant fractions of deep convective clouds and rain at their mature phase. Type 2 CSs (type 1 CSs) are constituted of larger deep convective cloud fractions with weaker (stronger) vertical development compared to type 1 CSs (type 3 CSs) in the Tropics (subtropics), resulting in larger rain fractions and less (more) presence of convective rain. Type 1 CSs have larger fractions of deep convective clouds and rain but with weaker vertical development in the subtropics than in the Tropics, showing that cold fronts organize convection more in area in the subtropics, but more in vertical extent in the Tropics. Life cycle variations of CS cloud and rain properties show tropical CSs with a more intense initial development and similar structural differences between the CS types and those found at their mature phase.
\end{abstract}

\section{Introduction}

Knowledge about convective systems (CSs) is important for understanding weather and climate and for improving weather forecast models over the world, espe-

Corresponding author address: Jose Ricardo Siqueira, Divisão de Meio Ambiente e Clima, Centro de Previsão de Tempo e Estudos Climáticos, Instituto Nacional de Pesquisas Espaciais, Avenida dos Astronautas, $1758 \mathrm{Jardim}$ da Granja, São José dos Campos/SP 12201-970, Brazil.

E-mail: jricardo@cptec.inpe.br cially in the world's tropical regions. Tropical precipitation generally occurs in the form of organized mesoscale CSs, which are characterized by two components: convective and stratiform regions (Zipser 1977; Leary and Houze 1979; Houze 1989, 1993). Convective regions range from a few kilometers to around $30 \mathrm{~km}$ in scale, have strong updrafts and downdrafts, and are characterized by heavy rainfall and strong vertical air motions. Stratiform regions may extend for hundreds of kilometers and have relatively weak vertical air motions and greater horizontal homogeneity, but their rainfall rates rarely exceed $10 \mathrm{~mm} \mathrm{~h}^{-1}$. These two re- 
gions have different latent heating profiles that impact the earth's climate differently (Tao and Simpson 1989; Houze 1989, 1993; Tao et al. 1993). The convective regime can be seen to heat the entire troposphere and is dominated by condensation and deposition processes. The stratiform regime usually cools the lower atmosphere and is dominated by evaporative cooling.

In 1970s and 1980s, CSs with different horizontal scales began to be studied by the scientific community using infrared (IR) and visible (VIS) images taken by passive sensors on board geostationary weather satellites (Houze 1977; Maddox 1983; Tollerud and Esbensen 1985; Velasco and Fritsch 1987). The most extensive collection of these weather satellite observations provided by the International Cloud Climatology Project (ISCCP) has been used to track CSs and describe their cloud and radiative properties over the whole Tropics (Machado and Rossow 1993; Garreaud and Wallace 1997; Machado et al. 1998). Since the launch of the Tropical Rainfall Measuring Mission (TRMM) satellite in late 1997, important studies have also been done using the TRMM microwave Precipitation Radar (PR) to describe the three-dimensional structure of rain produced by CSs over the Tropics (Thurai and Iguchi 2000; Meneghini et al. 2001), supplemented by studies using the TRMM Microwave Imager (TMI; e.g., Nesbitt et al. 2000; Fu and Liu 2001).

The combined data analysis of the images of passive and active sensors (radar) on board meteorological satellites has been a powerful tool to provide a wide variety of CS structural descriptions and investigate possible relationships between cloud properties and rainfall amounts. In a recent study, $\mathrm{Fu}$ and $\mathrm{Liu}$ (2001) combined the TRMM TMI brightness temperatures and TRMM PR precipitation profiles to study the variability of tropical precipitation and its impact on microwave brightness temperatures. Over South America (SA), Bellerby et al. (2000) made CS rainfall estimates with high temporal and spatial resolution by combining the TRMM PR precipitation profiles and Geostationary Operational Environmental Satellite (GOES) IR brightness temperatures. Recently, Morales et al. (2002) described the vertical rainfall structural characteristics of mesoscale CSs over the Amazon Basin during the Large-Scale Biosphere-Atmosphere (LBA) experiment. From the combined TRMM PR precipitation profiles and GOES brightness temperatures, the above authors noted strong dependence of convective activity within CSs on their lifetime and radius, such that longer and larger CSs began with a more intense initial development. The dependence of the convective activity of smaller CSs on the larger-scale environment during the initiation, maturation, and decay phases of CS life cycle was supplemented by other important studies (e.g., Byers and Braham 1949; Machado et al. 1998).

The goal of this paper is to describe the structural characteristics of the CS over SA related to cold-frontal incursions and their interaction with tropical convec- tion. The three most important types of front-tropical convection interaction are studied. Types 1,2 , and 3 consist of midlatitude frontal incursions that penetrate over SA and move with convection into lower tropical latitudes, midlatitude frontal incursions over SA that interact with Amazon convection and favor the South Atlantic convergence zone (SACZ) formation, and midlatitude frontal incursions that remain quasistationary over subtropical SA and exhibit weak interaction with tropical convection, respectively. Type 1 is frequent throughout the year and especially in austral spring and summer, while types 2 and 3 are more frequent in austral summer and winter, respectively.

By developing a 10-yr climatology for the three types of front-tropical convection interaction over SA using ISCCP C1 data (Rossow and Schiffer 1991) and National Centers for Environmental Prediction (NCEP) reanalyses (Kalnay et al. 1996), Siqueira and Machado (2004) observed that they exhibit distinct synoptic patterns and contribute strongly to the day-to-day convection variability over SA throughout the year. In Siqueira and Machado's mean satellite composites, the passage of a cold front over southeast SA that advances with convection into central SA, southern northeast $S A$, and the Amazon basin was the main spatial pattern of convection variability found for type 1 and indicated the front-tropical convection interaction during the type 1 events. The existence of a cold front over southeast SA accompanied by a quasi-stationary northwestsoutheast band of convection extended from the Amazon basin to central SA, southeast SA, and the South Atlantic for periods longer than 3 days was the main spatial pattern of convection variability found for type 2. Type 2 was associated with the SACZ synoptic formation, which is evidently maintained by the interaction between the cold fronts over southeast SA and the Amazon deep convection. The main spatial pattern of convection variability found for type 3 was a quasistationary band of convection over the subtropics and midlatitudes stimulated by cold fronts in subtropical SA that interact very little with tropical convection.

In Siqueira and Machado's (2004) mean circulation composites, a low-level transient cyclone over southeast SA that is maintained by the convergence of hot, wet air masses from the Amazon basin (produced from the equatorial air in the Atlantic Ocean modified by its travel over the SA continent and enriched in water vapor) and cold, dry air from the midlatitudes (cold front) during the type 1 to 3 events also evidenced the interaction between the fronts and the tropical convection over SA, especially for types 1 and 2 . This cyclone moves northeastward and is accompanied by intense southerly winds in the Tropics during the type 1 events, characterizing the penetration of the cold front and cold-air incursions into tropical SA for type 1, respectively. The lcyclone remains quasi-stationary over southeast SA during the type 2 events, but it is also accompanied by southerly winds (cold-air incursions) 
that support the SACZ formation for type 2. During the type 3 events, the cyclone remains quasi-stationary over southeast SA and the southerly winds are reduced (weak cold-air incursions), consistent with the weak interaction of the cold fronts with tropical convection in SA for type 3 .

In this paper, a wet-season climatology (austral summer, fall, and spring) for the three types of fronttropical convection interaction is described, and a composite cloud and rainfall description for CSs during these events is developed by combining ISCCP DX and TRMM passive and active sensors. In section 2 we describe the datasets used in the analysis. The identification of the three types of front-tropical convection interaction over SA and the methods employed for tracking the structural evolution of their corresponding CSs are detailed in section 3. The main structural characteristics of the CSs at their mature phase are described in section 4 , and the variability of the CS structure during their life cycle is discussed in section 5. Section 6 presents summaries and conclusions.

\section{Data}

ISCCP DX data and PR and TMI data from the TRMM satellite are used in this study. The DX data were acquired from the National Aeronautics and Space Administration Goddard Institute for Space Studies (NASA GISS), while the TRMM data are provided by the NASA Goddard Space Flight Center (GSFC). The data were extracted for the region $5^{\circ}-$ $40^{\circ} \mathrm{S}, 30^{\circ}-65^{\circ} \mathrm{W}$, for January 1998 through December 2000 (except June, July, and August). The DX data consist of radiances that are measured by passive radiometers on board geostationary satellites in VIS (wavelength $\cong 0.6 \mu \mathrm{m}$ ) and IR (wavelength $\equiv 11 \mu \mathrm{m}$ ) together with the retrieved cloud properties (Rossow and Schiffer 1999). The horizontal resolution of the data is $7 \mathrm{~km}$ sampled to about $30 \mathrm{~km}$ for the times 0000,0300 , $0600,0900,1200,1500,1800$, and 2100 UTC. The DX data are produced by the combination of satellitemeasured radiances of the ISCCP B3 data (from GOES-East for SA) with Television Infrared Observation Satellite (TIROS) Operational Vertical Sounder (TOVS) atmospheric temperature-humidity correlative dataset. All DX results in IR are collected for high cold clouds, that is, clouds with cloud-top temperature lower than $245 \mathrm{~K}$ (top heights above $8 \mathrm{~km}$ ): IRretrieved cloud-top temperature and pressure. The IRretrieved high cold cloud variables are obtained by assuming that high cold clouds are opaque to the upward IR radiation from the surface. Also collected are DX results in VIS for high cold clouds: VIS-adjusted ice cloud-top temperature and pressure, and VIS-retrieved ice cloud optical thickness. The VIS-adjusted ice cloud variables are obtained by evaluating VIS-retrieved ice cloud optical thickness, whose estimates are based on ice cloud reflectances in VIS.
The TRMM satellite is a non-sun-synchronous satellite orbiting at $350 \mathrm{~km}$ above the surface, thus covering tropical latitudes from $-38.75^{\circ} \mathrm{S}$ to $+38.75^{\circ} \mathrm{N}$. The TRMM PR is an electronically scanning radar operating at $13.8 \mathrm{GHz}$ (Iguchi et al. 2000). It scans $\pm 17^{\circ}$ from nadir with 49 positions, resulting in a $220-\mathrm{km}$ swath width and a horizontal resolution of $4.3 \mathrm{~km}$ at nadir. The vertical resolution along the radar beam is $250 \mathrm{~m}$. The sensitivity of the radar is such that the minimum detectable signal is about $20 \mathrm{dBZ}$ (corresponding to about $0.7 \mathrm{~mm} \mathrm{~h}^{-1}$ in rain rate). The PR rainfall products $2 \mathrm{~A} 25$ and $2 \mathrm{~A} 23$ are employed in this study. The $2 \mathrm{~A} 25$, which is a product of attenuation-corrected precipitation profiles, contains vertical profiles of rainfall rate $R$ that are calculated from the radar reflectivity $Z$ profiles by using a $Z-R$ relationship based on a hybrid of the Hitschfeld-Bordan method and a surface reference method (Iguchi et al. 2000). Because of the surface contamination, rainfall rate cannot be derived for levels close to the surface. For this reason, we only analyze $P R$ data above $2 \mathrm{~km}$. The $2 \mathrm{~A} 23$ product is a rain classification based on the vertical pattern of the profiles (Awaka et al. 1998). A rain profile is classified as stratiform if PR detects a bright band near the freezing level. If no bright band exists and any value of attenuationcorrected radar reflectivity in the beam exceeds 39 $\mathrm{dBZ}$, the profile is classified as convective.

The TRMM TMI is a microwave passive radiometer that measures brightness temperatures at the following five frequencies: $10.7,19.4,21.3,37.0$, and $85.5 \mathrm{GHz}$. Dual polarizations are measured at $10.7,19.4,37$, and $85.5 \mathrm{GHz}$; only vertical polarization is observed at 21.3 $\mathrm{GHz}$. The TMI scans $\pm 52.8^{\circ}$ from nadir with 104 (208) positions for the low- (high) resolution channels, resulting in a $720 \mathrm{~km}$ swath width and a horizontal resolution ranging from $4.8 \mathrm{~km}$ at $85.5 \mathrm{GHz}$ to $39 \mathrm{~km}$ at $10.7 \mathrm{GHz}$. The TMI product $1 \mathrm{~B} 11$ contains the calibrated and navigated brightness temperatures for all the channels, but only the high-resolution channel with vertical polarization at $85.5 \mathrm{GHz}$ is used in the analysis.

\section{Front-tropical convection interactions over South America}

\section{a. Identification of events}

The identification of the events representative of the three types of front-tropical convection interaction over SA during the austral wet season of the 1998-2000 yr was done by producing latitude-time diagrams for high cold cloud fractions from the DX data for every 3 h. The high cold cloud fraction is defined as the ratio between the number of DX cloudy pixels with IR cloud-top temperature lower than $245 \mathrm{~K}$ and the total number of DX pixels inside a $10^{\circ}$ longitudinal region. The high cold clouds often cluster at scales of 20-200 $\mathrm{km}$ or in more organized mesoscale $(200-2000 \mathrm{~km})$ systems and are related to convective processes over the 
(a)

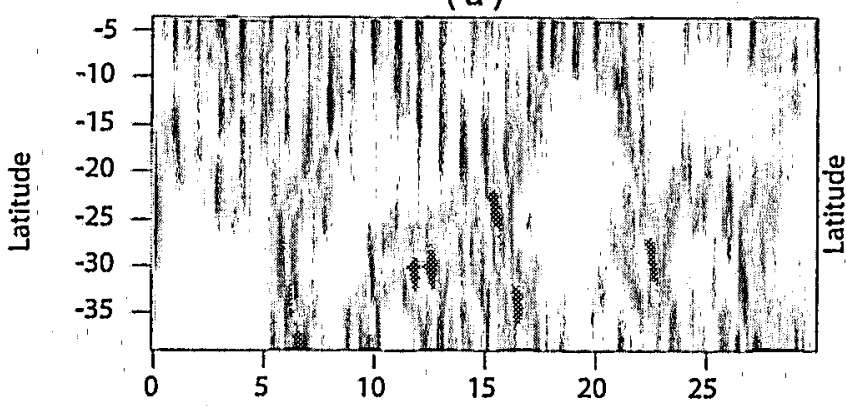

Time (days) (b)

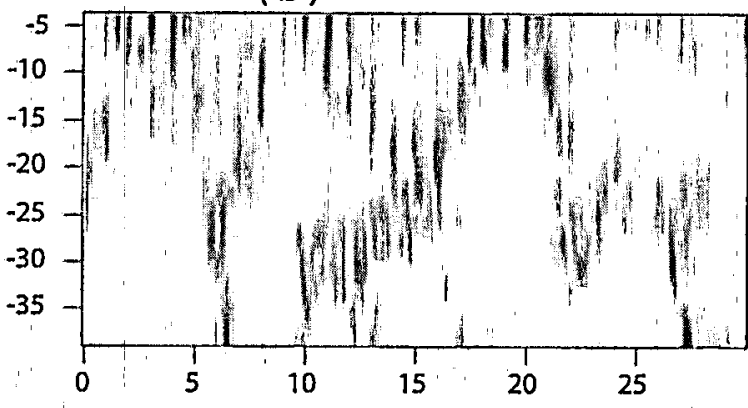

Time (days)

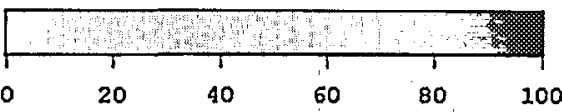

Cloud top fraction (B)

FIG. 1. Latitude-time diagrams produced for (a) high cold cloud fractions and (b) very high cold cloud fractions over the longitudinal window $48.75^{\circ}-58.75^{\circ} \mathrm{W}$ for Apr 1998 .

Tropics, since the majority of the thin cirrus clouds are eliminated by this test because they are semitransparent to IR radiances (Houze 1993; Machado and Rossow 1993; Rossow and Schiffer 1999). To avoid the direct influence of the Andes Mountains on the day-to-day convection variability and to get a better-defined largescale organization of the high cold clouds by fronts over SA before their crossing to the Atlantic Ocean, a $10^{\circ}$ longitudinal window between $48.75^{\circ}$ and $58.75^{\circ} \mathrm{W}$ was used to compute zonal means of the high cold cloud fractions for the latitude-time diagrams, following the methodology of Siqueira and Machado (2004).

Figure 1 shows the latitude-time diagram produced for high cold cloud fractions inside $5^{\circ}-40^{\circ} \mathrm{S}$ for every $2.5^{\circ}$ for April 1998. The latitude-time diagram produced for a second definition of high cold cloud cover (very high cold cloud fraction), which will be employed in the next analysis steps, is also shown in Fig. 1. The very high cold cloud fraction represents the fraction of the total number of DX cloudy pixels with cloud-top temperatures lower than $220 \mathrm{~K}$ (cloud-top heights above $12 \mathrm{~km}$ ). The very high cold clouds refer to individual convective cells in the atmosphere, which are about $2-20 \mathrm{~km}$ in size and usually produce a characteristic "cumulonimbus" cloud, "cumulus tower," or "thunderstorm" (Scorer 1977; Houze 1993; Machado and Rossow 1993). The influence of the three types of front-tropical convection interaction on the high cold clouds organization over SA in April 1998 can be observed in Fig. 1. High cold clouds moving northward from the midlatitudes to lower tropical latitudes between days 16 and 18 correspond to the occurrence of one type 1 event, while the southward development of high cold clouds from the Tropics to the subtropics from days 20 to 22 characterizes the occurrence of one type 2 event. The occurrence of one type 3 event is represented by a quasi-stationary feature of high cold clouds (with respect to the meridional direction) in the subtropics and midlatitudes from days 10 to 12 . The influence of the three types on the very high cold cloud organization is also relevant, suggesting the importance of the three types for also organizing clouds that are frequently associated with deep convection (Fig. 1). The similarity between the latitude-time diagrams for high cold clouds and very high cold clouds illustrates that the analysis is not sensitive to the two particular cloud-top temperature thresholds used for identification of the types 1 to 3 events.

To evidence the behavior of cold fronts during the occurrence of the three types of front-tropical convection interaction over SA, we have made a composite analysis for the total $850-\mathrm{hPa}$ component of the horizontal wind lat 1800 UTC during the type 1 to 3 events in April 1998 using NCEP reanalysis, as shown in Fig. 2. During the type 1 event, a low-level cyclone over southeast SA that is maintained by the convergence of hot, wet air masses from the Amazon and cold, dry air from the midlatitudes is observed moving toward northeast $\mathrm{SA}$, characterizing the penetration of a cold front and cold-air incursions into lower tropical latitudes and its interaction with tropical convection. During the type 2 event, a relatively weak convergence zone is observed over southeast SA and is supported especially by hot, wet air masses from the Amazon and also by cold-air incursions brought by a cold front that penetrated southeast SA some days before the onset of the type 2 event. For type 3 , a quasi-stationary cyclone is observed in the midlatitudes, and there is very little cold-air incursion toward tropical SA, representative of a quasistationary cold front and its weak interaction with 
Type 1

day 16

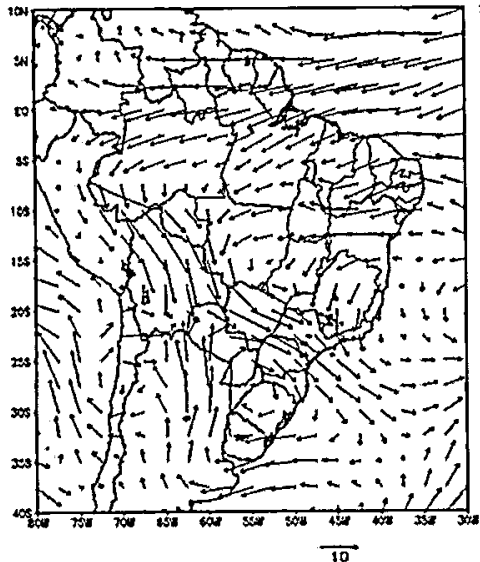

$\overrightarrow{10}$ day 17

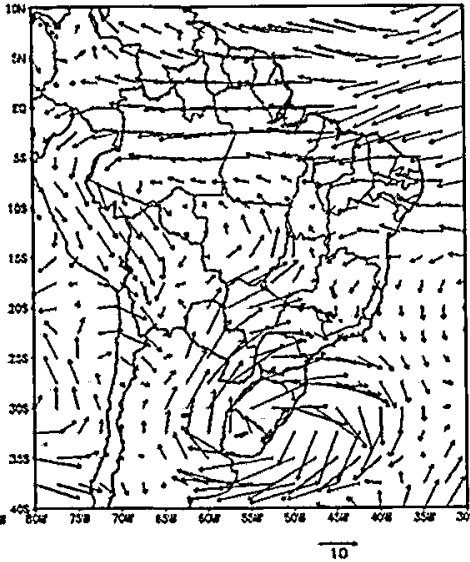

10 day 18

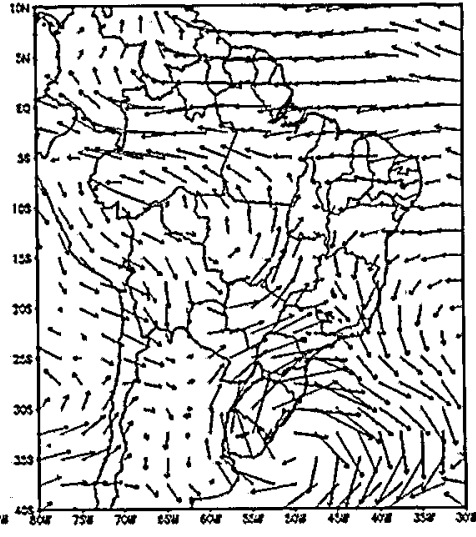

$\longrightarrow$

Type 2

day 20

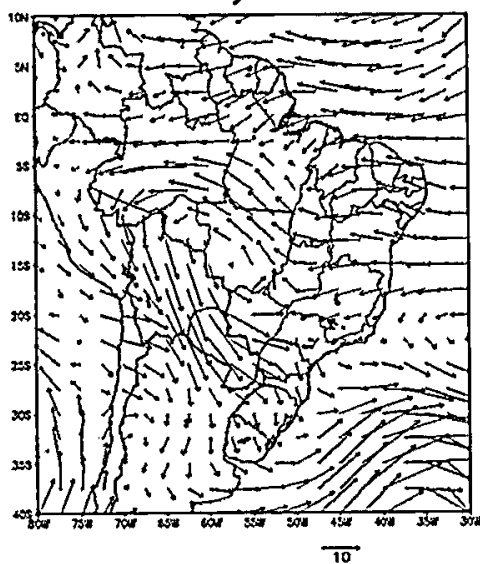

$\overrightarrow{10}$ day 21

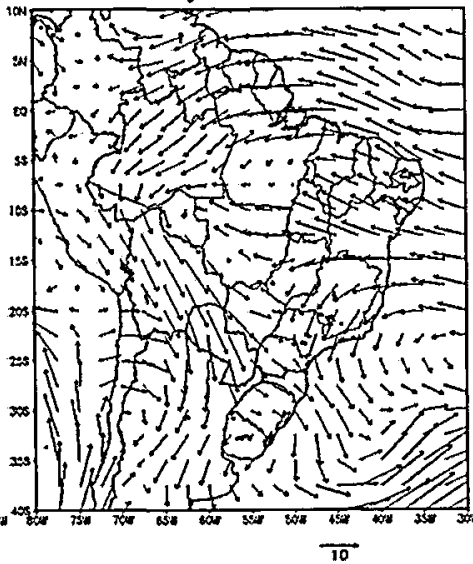

day 22

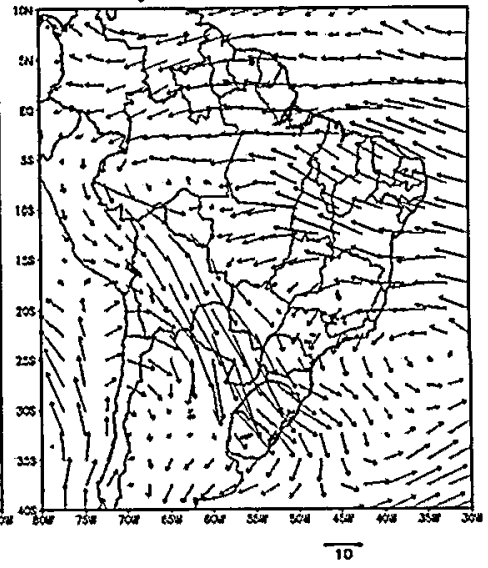

Type 3

day 10

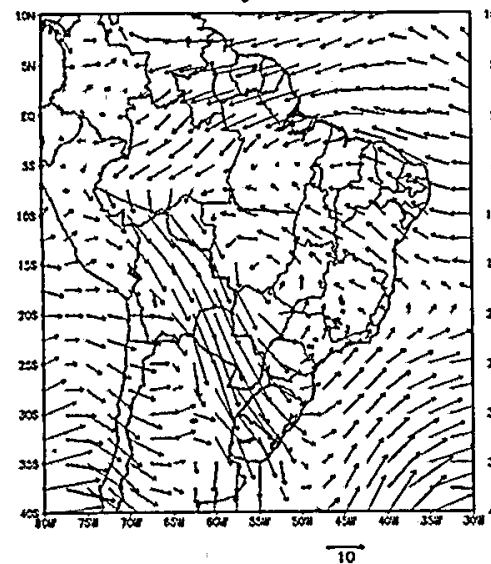

day 11

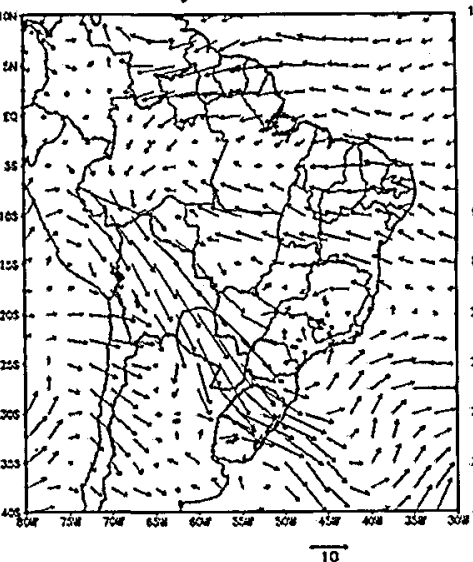

day 12

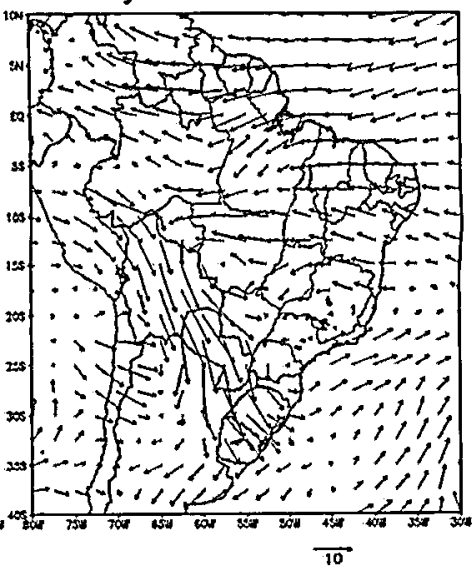

FIG. 2. Total 850 -hPa component of the horizontal wind at 1800 UTC for day 16 to day 18 , day 20 to day 22 , and day 10 to day 12 of occurrence of one type 1, one type 2, and one type 3 event over SA, respectively, during Apr 1998. 
tropical convection. The main circulation features observed over SA during the type 1 to 3 events are consistent with those found by Siqueira and Machado (2004).

Since the three types of front-tropical convection interaction establish a direct relationship with the meridional evolution of high cold clouds and very high cold clouds (Fig. 1), the identification of the three types of events was done using an objective method developed and detailed by Siqueira and Machado (2004). The main idea of the method consists of capturing the time of a local maximum value of high cold cloud fraction for a given latitude and finding the time of a similar maximum value at a neighboring latitude. As a result, the meridional evolution of high cold clouds over the time is known and associated with the occurrence of type 1 , 2 , or 3 events. The identification of the three types of events over SA during the austral wet season resulted in a total of 62 type 1,15 type 2, and 19 type 3 events.

\section{b. Tracking and description of $C S$}

The IR cloud-tracking method developed and detailed by Machado et al. (1998) was applied to IRretrieved cloud-top temperatures from the DX data to track and describe basic properties of the CS associated with the three types of front-tropical convection interaction over continental SA during the austral wet season of the 1998-2000 yr. The IR cloud-tracking method detects CS by applying two thresholds for IR cloud-top temperatures: $245 \mathrm{~K}$, equivalent to high cold clouds, and $220 \mathrm{~K}$, equivalent to very high cold clouds. According to the methodology of Machado et al. (1998), each cluster of high cold clouds that exhibits similar cloud morphologic characteristics, throws the time in the DX data, and contains a cluster of very high cold clouds (convective cells) at some time of its life cycle is classified as a CS. If one of the CSs splits, the IR cloudtracking method will track the system that most closely resembles the original, usually the larger one; the other CSs will be tracked as separate systems. If one of the CSs merges with a smaller system, the IR cloudtracking method continues to track, but if it merges with a larger system, its life cycle is terminated.

The main CS basic properties obtained from the IR cloud-tracking method and used in this paper are system lifetime, effective radius (radius of a circle with the same area as the CS), very high cold cloud fraction, time of the mature phase, propagation speed, and propagation directions of the high cold clouds and largest very high cold clouds with respect to the east. The very high cold cloud fraction of the CS is defined as the ratio between the number of DX very high cold cloudy pixels and the total number of DX cloudy pixels within the CS. We have complemented the IR description by estimating the distribution of cloud types and radiative properties of the CS identified in daytime using VISadjusted cloud-top temperature and pressure and VISretrieved cloud optical thickness from the VIS-DX pix- els. A VIS-DX pixel population equivalent to at least half $(50 \%)$ of the CS area was required to get a comprehensive VIS-DX description. The cloud-type description was done using the ISCCP classification: thin cirrus, thick cirrus (cirrocumulus, cirrostratus), and deep convective clouds (cumulonimbus, cumulus congestus) are high-topped clouds (cloud-top pressure lower than $440 \mathrm{hPa}$ and cloud-top temperatures lower than around $260 \mathrm{~K}$ ) with cloud optical thicknesses of $0-3.6,3.6-23$, and 23-379, respectively (Rossow and Schiffer 1999). A CS thin (thick) cirrus cloud fraction was defined as the ratio between the number of VISDX thin (thick) cirrus cloudy pixels and the total number of VIS-DX cloudy pixels within CS. Similarly, a deep convedtive cloud fraction was defined as the ratio between the number of VIS-DX deep convective cloudy pixels and the total number of VIS-DX cloudy pixels within CS.

The next analysis step consists of obtaining the rainfall characteristics of the CS identified in the DX data by using collocated TRMM PR rainfall products 2 A23 and $2 \mathrm{~A} 25$ and brightness temperatures from the TRMM TMI product 1B11. First, we match PR and DX pixels by searching for all $P R$ pixels with centers inside the DX pixels within a time interval of $\pm 1.5 \mathrm{~h}$ from the CS time. The time interval was defined according to the time resolution of the DX data $(3 \mathrm{~h})$ to get the maximum possible number of $P R$ measurements throughout the CS life cycle. A PR pixel population equivalent to at least half the CS area was also required to get a comprehensive description by $P R$ variables. All matched $P R$ and DX pixels were extracted to estimate fractional distributions of the following variables for convective and stratiform rain within the CS: rain type and maximum rainfall rate. The CS convective (stratiform) rain fraction was defined as the ratio between the number of $\mathrm{PR}$ convective (stratiform) raining pixels and the total number of $P R$ raining pixels within the CS. A rain fraction was calculated as the ratio between the number of $P R$ raining pixels and the total number of PR pixels within the CS. Mean stratiform and convective rainfall rate profiles (above $2 \mathrm{~km}$ ) have also been computed for the CS. At the same time, we have also collocated TMI with the PR data to complement the $C S$ rainfall description by $P R$. For a given raining $P R$ pixel belonging to the CS, we select all TMI pixels that have a distance between their center and the center of the PR pixel smaller than one-half of the radiometer's spatial resolution at $85.5 \mathrm{GHz}$. For all matched TMI and PR raining pixels, we compute fractional distributions of the means and mean deviations of brightness temperature at $85.5 \mathrm{GHz}$. The TMI description is based on the observation that $85-\mathrm{GHz}$ brightness temperatures vary with respect to the rain intensity produced by CS. Colder (warmer) $85-\mathrm{GHz}$ brightness temperatures are mostly associated with intense (weak) rain because the $85-\mathrm{GHz}$ observations are sensitive mainly to scattering of the microwave radiation by large 
TABLE 1. Distribution of the CS population identified over continental South America on day -2 to day +2 of the type 1 to 3 events in the austral wet season for the 1998-2000 yr. The availability of VIS-DX and TRMM PR measurements for CS description at the initiation (INI), maturation (MAT), and decay (DEC) phases of the CS life cycle is also shown. TD and SD denote tropical CS and CS over the subtropics/midlatitudes, respectively.

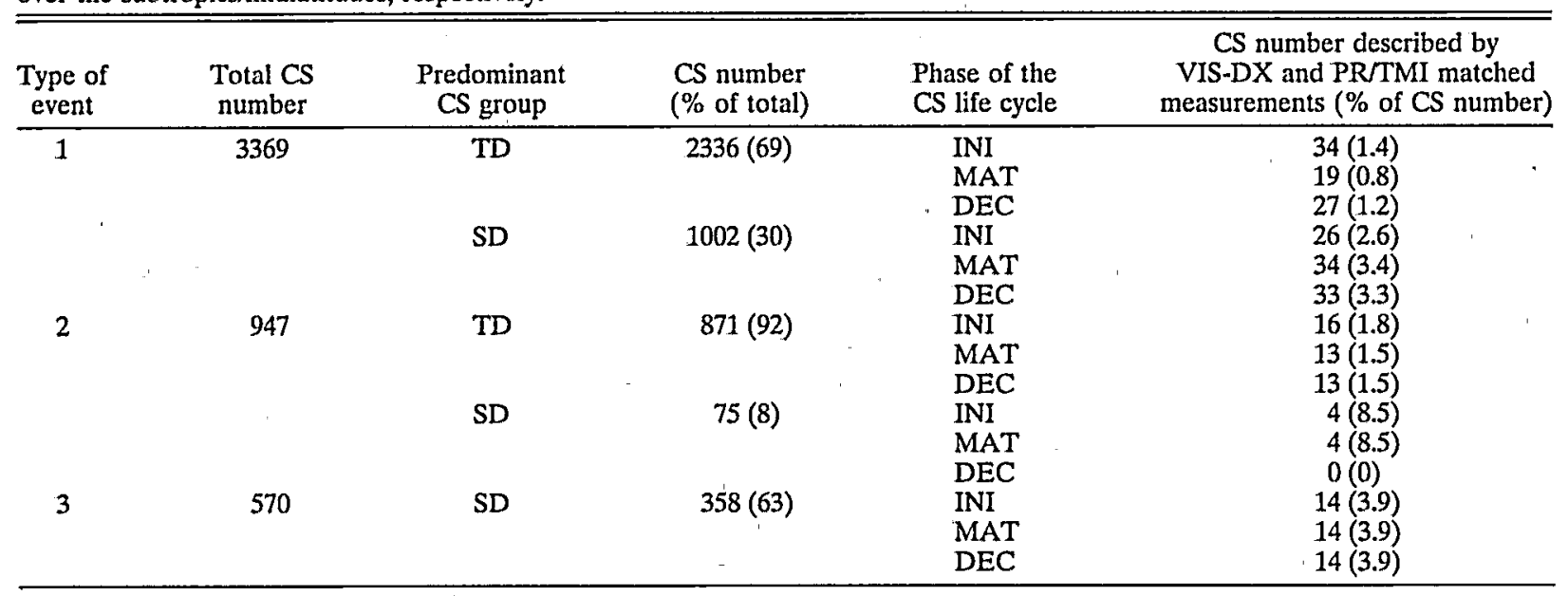

ice particles in the atmosphere (Hong et al. 1999; Fu and Liu 2001).

Only the CS that formed between day -2 and day +2 of central day of the type 1 to 3 events are studied, and a wet-season climatology is built for each type. By selecting all CSs between days -2 and +2 , we have based the choice on the minimum time scale of convective variability associated with the type 1 to 3 events estimated by Siqueira and Machado (2004), which is 5 days. This procedure allows us to study all CSs over SA that are more directly related to frontal incursions. To study the main regions in the continental SA influenced by types 1 to 3 , we have restricted analysis to the CSs situated over longitudes east of $65^{\circ} \mathrm{W}$ and inside $5^{\circ}-$ $40^{\circ} \mathrm{S}$. Only the type 1 (type 2) CSs situated between the extreme latitudinal positions of northward propagation (southward enhancement) of convection in the latitude-time diagrams lagged by $5^{\circ}$ are extracted, while only the type 3 CSs inside $20^{\circ}-35^{\circ} \mathrm{S}$ lagged by $5^{\circ}$ are selected. By employing a latitudinal lag of $5^{\circ}$, we select not only the CSs situated between the extreme latitudinal positions of northward propagation (type 1) or southward enhancement of convection (type 2) given by the latitude-time diagram, but also the CSs situated over latitudinal positions up to $5^{\circ}$ smaller (larger) than the inferior (superior) latitudinal position of the latitude-time diagram. For type 3 , the lag of $5^{\circ}$ resulted in a selection of all CSs situated between $15^{\circ}$ and $40^{\circ} \mathrm{S}$ during the type 3 events. This procedure was undertaken to select a maximum CS number related to frontal incursions over SA.

To restrict analysis to CSs within a large-scale organization by fronts, only the CSs with effective radius larger than $90 \mathrm{~km}$ (larger area than $25460 \mathrm{~km}^{2}$ ) are studied. The choice of a $90-\mathrm{km}$ threshold for the CS effective radius is enough to eliminate the majority of the CSs over SA related only to local convective pro- cesses and select larger mesoscale CSs that are usually associated with large-scale features. For instance, Machado and Rossow (1993) showed that more than $70 \%$ of CS numbers are eliminated if a radius threshold of $100 \mathrm{~km}$ is used. A close CS radius threshold was also used successfully by Machado et al. (1998) to track CS over SA related to frontal incursions, Bolivia high, SACZ, and east waves. All CS parameters described above are collected for the initiation (INI), maturation (MAT) and decay (DEC) phases of the CS life cycle. The first (last) time at which CSs are present in the DX data is defined as INI (DEC) phase, while the time at which CSs acquire their largest very high cold cloud fraction corresponds to the MAT. Since the IR cloudtracking method identifies CS on the DX data separated by $3 \mathrm{~h}$, the first detection may be at an advanced stage of convective development, so some CSs exhibit coincident INI and MAT phases.

The statistical distributions of the CS populations associated with the three types of front-tropical convection interaction over continental SA during the austral wet season of the 1998-2000 yr are shown in Table 1. The majority of the 3369 type 1 CSs are found over the Tropics (between $5^{\circ}$ and $23^{\circ} \mathrm{S}$ ) rather than over the subtropics/midlatitudes (between $23^{\circ}$ and $40^{\circ} \mathrm{S}$ ). A much higher fraction of the 947 type 2 CSs are over the Tropics, and the majority of the 570 type 3 CSs are over the subtropics/midlatitudes. Practically all CSs exhibit lifetimes shorter than 1 day (subdiurnal). The types 1 and $3 \mathrm{CS}$ populations are significantly reduced over the midlatitudes $(25 \%-31 \%$ of the CS over the subtropics/ midlatitudes), while no type 2 CSs occur in the midlatitudes (between $30^{\circ}$ and $40^{\circ} \mathrm{S}$ ). Because of the unavailability of VIS-DX measurements at nighttime, the poor time resolution of the TRMM sensors, and the requirement on minimum pixel population used in the analysis, the CS populations with VIS-DX and TRMM PR mea- 
surements available at a same phase (matched) are very low compared to the total CS populations. To build a more comprehensive CS description using all these instruments, we have also selected all CS that contain VIS-DX and TRMM PR measurements in at least one phase of their life cycle (matched or not matched) and that satisfy the minimum requirement of VIS-DX and TRMM PR pixel populations. This procedure maintains an adequate CS population with VIS-DX and PR matched measurements (Table 1), which is important to make the descriptions consistent, and increases considerably the total CS population described by VIS-DX and TRMM PR in all CS groups (not shown). In section 4 we present the CS structural characteristics during their mature phase, while the most important aspects of their life cycle variability are discussed in section 5 .

\section{Structural characteristics of the front-tropical convection interactions}

The structural characteristics of the CS associated with the three types of front-tropical convection interaction over SA at their mature phase are presented as follows. The CS analysis is done in two latitude zones: Tropics and subtropics/midlatitudes. The main reason for this separate CS analysis is the necessity of investigating deep convection over SA related to fronts during two distinct synoptic configurations: fronts initially penetrating over SA (interacting with convection especially over the subtropics and midlatitudes) and fronts interacting with tropical convection either by moving directly into lower tropical latitudes (type 1 ) or by establishing only cold-air incursions over the Tropics (types 2 and 3). For type 1, which is responsible for a high CS population over the Tropics and subtropics/midlatitudes, results are shown for both latitude zones. For type 2, whose tropical CS population is much larger than over the subtropics, results are presented only for the Tropics. As type 3 stimulates little tropical convection, type 3 results are presented only for the subtropics/midlatitudes. Comparative analyses between the CS structures are done for the Tropics [types 1 tropical diurnal (TD) and 2 TD CS] and subtropics/midlatitudes [types 1 subtropical diurnal (SD) and 3 SD CS]. The latitudinal variation of the CS structures is also examined, but using only the type 1 CS (1 TD and $1 \mathrm{SD})$ to make a coherent, consistent comparison between CSs belonging to the same synoptic pattern that is much more frequent during the year and has a larger CS population available in the Tropics and subtropics (fronts moving into lower tropical latitudes).

\section{a. Tropical CS}

Figure 3 shows cumulative distributions of the CS number versus the time of day of their mature phase, their lifetime, and their effective radius for the four CS groups studied. The majority of the tropical CSs attain their largest very high cold cloud fraction in the late afternoon and early evening, consistent with the diurnal cycle of deep convection over tropical land areas described by Garreaud and Wallace (1997). The tropical CSs last mainly 3-6 h (75\% of CS), but some last 9-24 h. All tropical CSs are mesoscale in size with predominant effective radius from 90 to $150 \mathrm{~km}$ ( $86 \%$ of CS) and contain 'very high cold cloud fractions larger than $30 \%$ in about $90 \%$ of CSs during their mature phase (not shown). The distributions of the time of mature phase, lifetime, effective radius, and very high cold clouds within the tropical CSs show the effect of the cold fronts advancing into lower tropical latitudes and the SACZ formation on the production of mesoscale tropical CSs with subdiurnal lifetimes and significant fractions of clouds that are frequently associated with diurnal cycle of deep convection.

The high cold clouds within the tropical CSs were verified moving toward lower (type 1) and higher (type 2) latitudes for $23 \%$ of type 1 and $37 \%$ of type 2 tropical CSs, respectively (not shown). The type 1 very high cold clouds were observed moving toward lower latitudes more often ( $+6 \%$ of type 1 tropical CSs) than type 1 high cold clouds over the Tropics, showing the ability of the cold fronts in moving with deep convection into lower tropical latitudes. The type 1 tropical CSs situated over longitudes east of $55^{\circ} \mathrm{W}$ ( $40 \%$ of type 1 tropical CSs) form and are directly associated with the motion of the cold fronts toward northeast SA, while the remaining type 1 tropical CSs originate and are more directly related to midlatitude cold-air incursions brought by cold fronts into central SA and the Amazon basin (Siqueira and Machado 2004). A similar but stronger contrast $(+11 \%)$ was observed for the type 2 very high cold clouds moving toward higher latitudes in the Tropics with respect to the type 2 high cold clouds (not shown). The direction distributions of the very high cold clouds within the type 2 tropical CSs reveal that the SACZ formation is often characterized by propagation of tropical deep convection toward the subtropics that is maintained by convergence of hot, wet air masses from the Amazon basin and midlatitude cold-air incursions over tropical SA, as observed by Siqueira and Machado (2004).

Another important difference between the direction distributions of the types 1 and 2 tropical CS is that the largest distribution of meridional propagation of very high cold clouds and high cold clouds is within the type 2 CSs, characterizing the CS produced by the SACZ formation as a CS without preferential direction of propagation over the Tropics (not shown). The majority of the tropical CSs advancing toward lower and higher latitudes move between $-30^{\circ}$ and $+30^{\circ}$ with respect to the zonal direction (not shown). Despite the large-scale convective cloudiness, organization by cold fronts moving into lower tropical latitudes (type 1) and the SACZ formation (type 2) is oriented at the directions southeast-northeast and southeast-northwest (for type 1) and northwest-southeast (for type 2); as ob- 
(a)

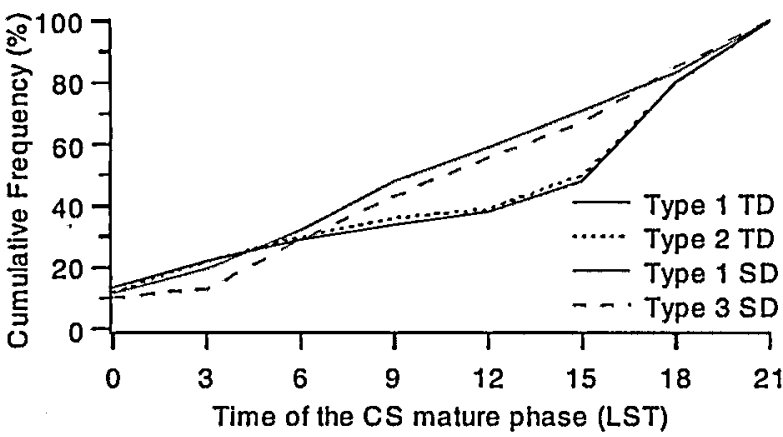

(b)

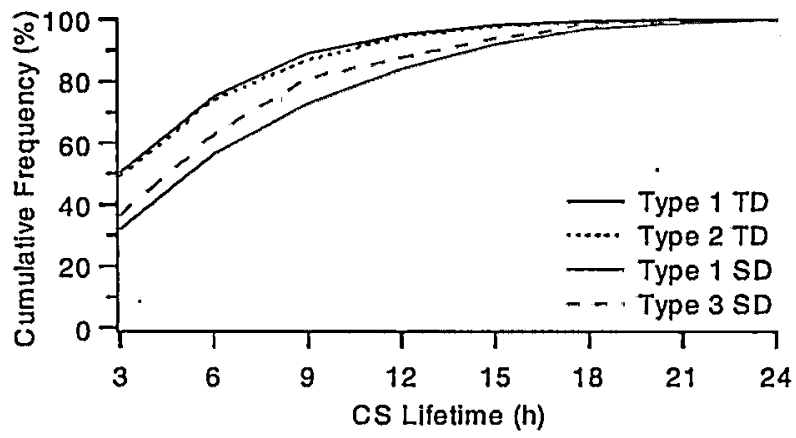

(c)

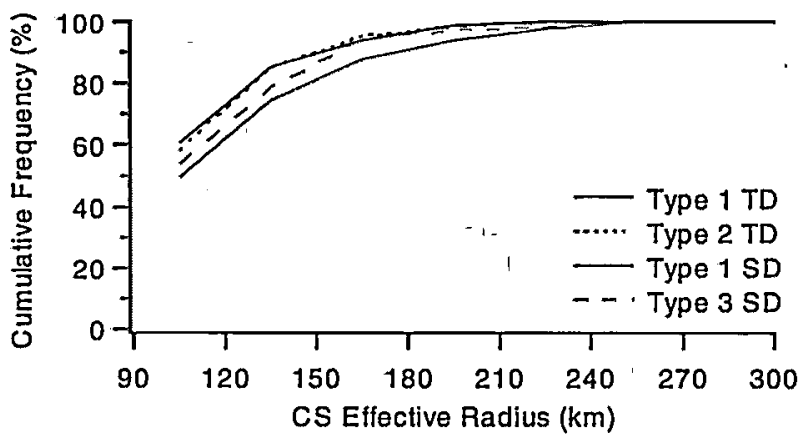

FIG. 3. Cumulative distributions of the CS number vs time of the (a) mature phase, (b) lifetime, and (c) effective radius at the mature phase of the CS life cycle obtained from the IR cloud-tracking method for the four CS groups studied. Statistics are accumulated every $3 \mathrm{~h}$ and for size ranges of $30 \mathrm{~km}$.

served by Siqueira and Machado (2004), the convective cloudiness organization in mesoscales by these two important front-tropical convection interactions is oriented predominantly around the zonal component. The majority of the types 1 and 2 tropical CSs move with propagation speeds $<10 \mathrm{~m} \mathrm{~s}^{-1}$, consistent with their modulation by cold-frontal incursions (not shown).

The methodology applied to track CSs eliminated the majority of the thin cirrus clouds that may have a less direct relationship with convection. Table 2 shows that $94 \%-100 \%$ of all CSs (over the Tropics and subtropics/ midlatitudes) have thin cirrus cloud fractions $<30 \%$

TABLE 2. Frequency distributions of the CS number vs thin and thick cirrus cloud fractions at the mature phase of the CS life cycle estimated from the VIS-DX pixels for the four CS groups studied.

\begin{tabular}{lcc}
\hline \hline & \multicolumn{2}{c}{$\begin{array}{c}\% \text { of the CS number described } \\
\text { by VIS-DX measurements }\end{array}$} \\
\cline { 2 - 3 } CS group & $\begin{array}{c}\text { Thin cirrus cloud } \\
\text { fraction (\%) }\end{array}$ & $\begin{array}{c}\text { Thick cirrus cloud } \\
\text { fraction (\%) }\end{array}$ \\
\hline & $<30$ & $>30$ \\
Type 1 TD & 94 & 73 \\
Type 2 TD & 100 & 57 \\
Type 1 SD & 96 & 38 \\
Type 3 SD & 94 & 62 \\
\hline
\end{tabular}

during their mature phase. Thick cirrus clouds are present within all the tropical CS, with $57 \%-73 \%$ of CSs containing cloud fractions $>30 \%$ (Table 2). The type 1 CSs exhibit the largest thick cirrus cloud fractions. Since the thick cirrus clouds may be produced by the spreading out of anvil cumulonimbus clouds and may be associated with precipitation, this cloud type must not be neglected despite their lower optical thicknesses (Houze 1977). The tropical CSs also include large fractions of deep convective clouds during their mature phase, as shown by their cumulative distributions in Fig. 4 (life cycle variability will be discussed later). About $72 \%-79 \%$ of CSs have deep convective cloud fractions $>30 \%$ (larger for the type $2 \mathrm{CS}$ ) and only $0 \%-8 \%$ of CSs do not contain this cloud type, which may have been missed by the coarse 3-h time sampling of the DX data. The tropical CSs produced by cold fronts that move into lower tropical latitudes and the tropical CSs associated with the SACZ formation are truly constituted by significant fractions of deep convective clouds characterized by strong vertical development as cumulonimbus and cumulus congestus, which are larger within the CSs produced along the SACZ formation.

The cumulative distributions of the minimum cloudtop temperatures of the deep convective clouds within 
(a)

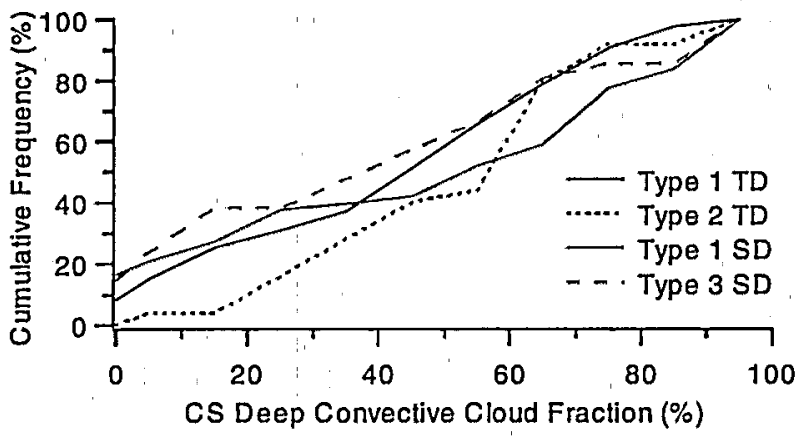

( b)

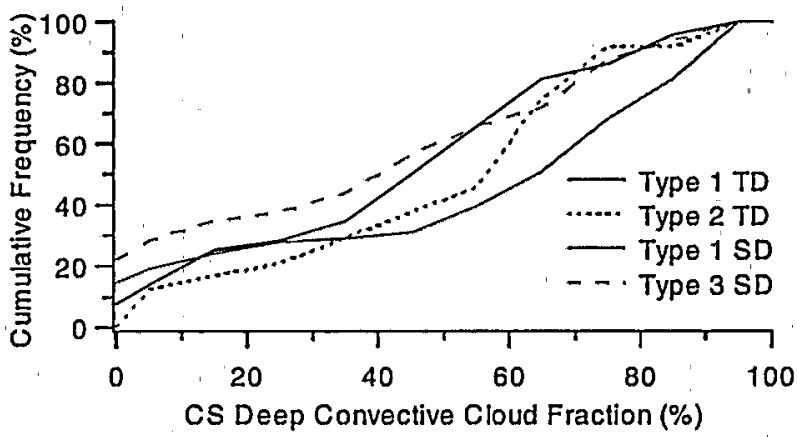

(c)

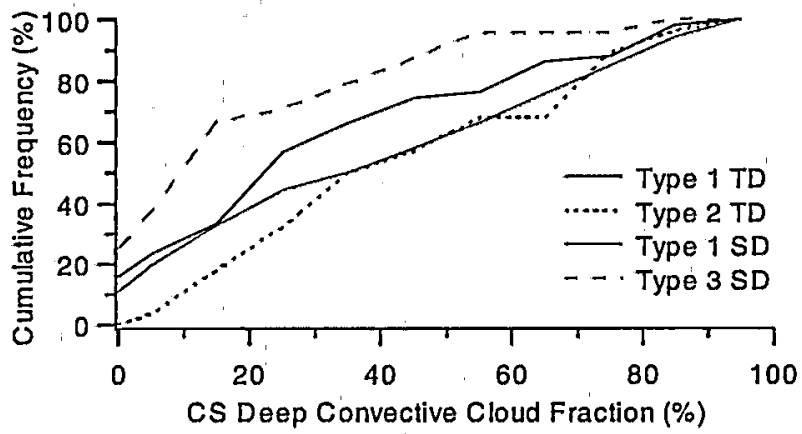

FIG. 4. Cumulative distributions of the CS number vs deep convective cloud fractions at the (a) initiation, (b) maturation, and (c) decay phases of the CS life cycle estimated from the VIS-adjusted DX pixels for the four CS groups. Statistics are accumulated for fraction ranges of $10 \%$.

the CSs during their mature phase shown in Fig. 5 reveal tropical CSs with cloud-top temperatures preferentially between 186 and $210 \mathrm{~K}$. A significantly higher CS number with minimum cloud-top temperatures colder (warmer) than $198 \mathrm{~K}$ is noted within the type 1 CSs (type 2 CSs). A similar behavior is exhibited by the optical thickness of the deep convective clouds within the CS, with the type 1 CS containing more optically thicker clouds than type 2 CS in the range 63-123 (Fig. $5)$. This characterizes the tropical CS produced along the SACZ formation as the CS with larger fractions of deep convective clouds but rather less vertical development than the tropical CS produced by cold fronts that advance into lower tropical latitudes. The quasi-

\section{(a)}

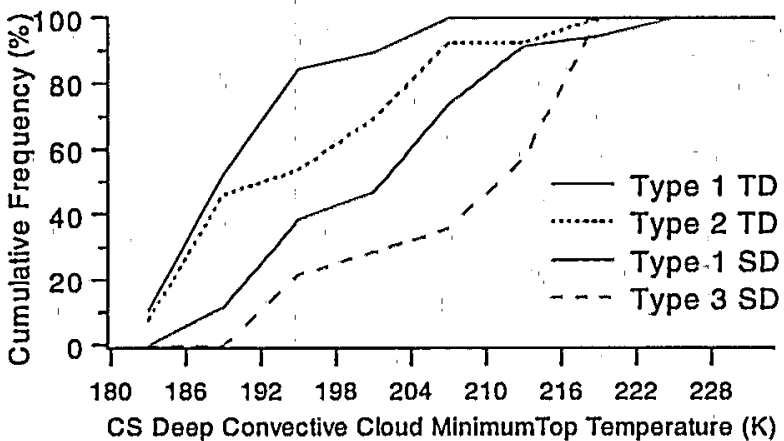

(b)

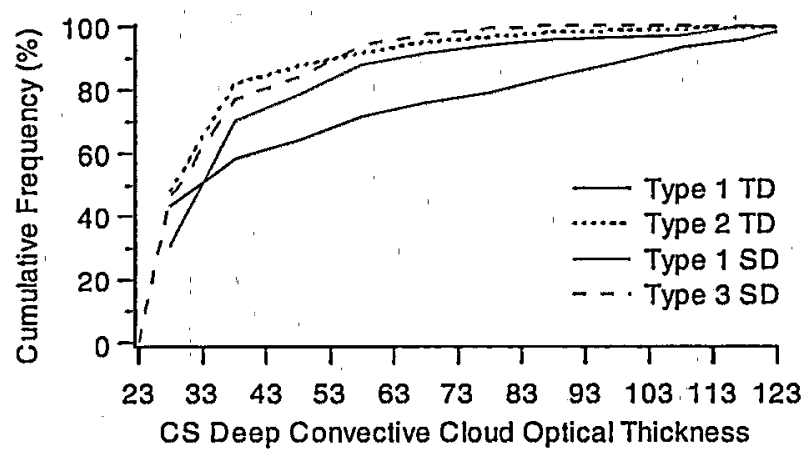

Fig. 5. (a) Cumulative distributions of the CS number vs the deep convective cloud minimum cloud-top temperature and (b) the deep convective cloud VIS-DX pixels number within CS vs deep convective cloud optical thickness obtained from the VIS-adjusted DX pixels at the mature phase of the CS life cycle for the four CS groups. Statistics are accumulated for temperature ranges of $6 \mathrm{~K}$ and optical thickness ranges of 10 units. 
(a)

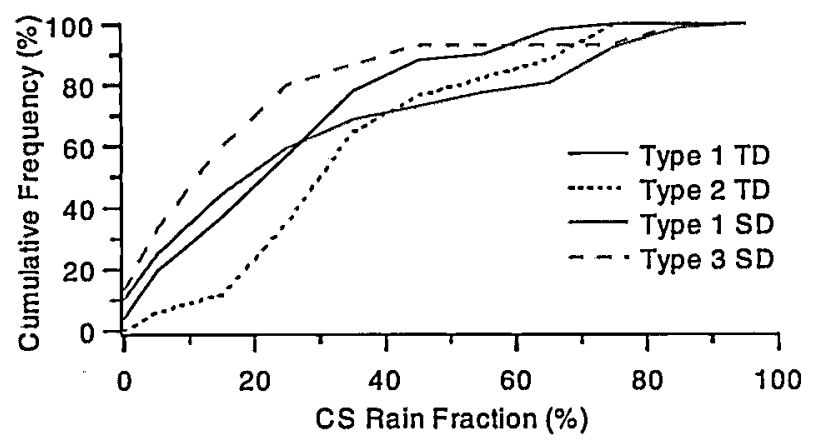

(b)

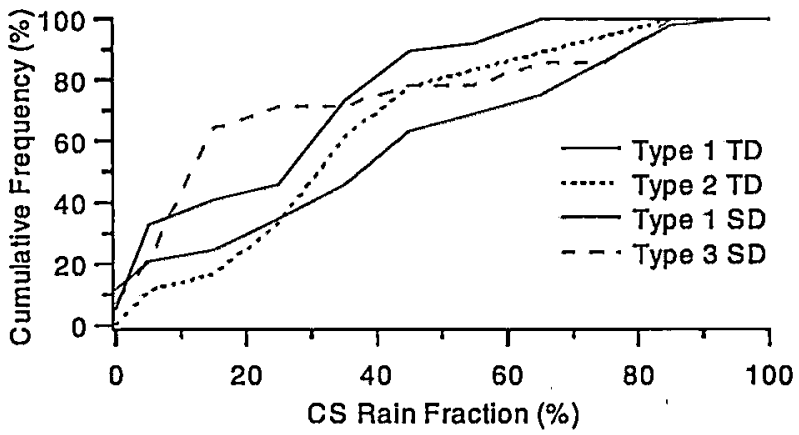

(c)

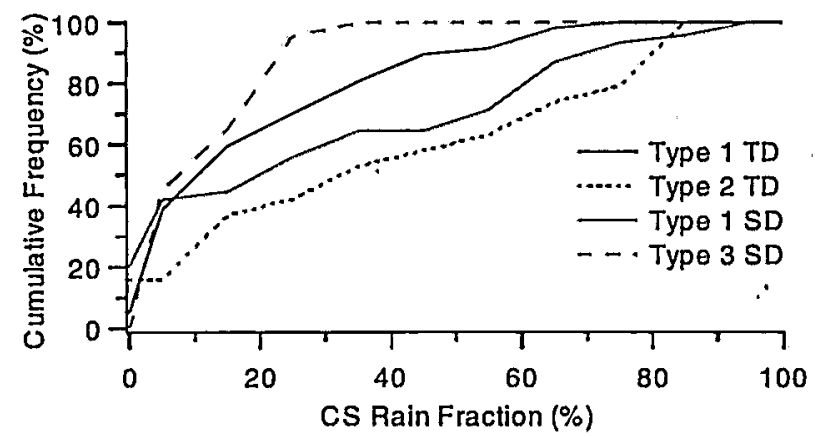

Fig. 6. Cumulative distributions of the CS number vs rain fractions at the (a) initiation, (b) maturation, and (c) decay phases of the CS life cycle obtained from collocated TRMM PR pixels for the four CS groups. Statistics are accumulated for ranges of $10 \%$.

stationary convective cloudiness organization over tropical SA by the SACZ mechanisms tends to stimulate deep convection over larger areas and establish more uniform distribution of deep convective clouds with fewer intense convection episodes over the Tropics (Siqueira and Machado 2004). In addition, the cold fronts that move into lower tropical latitudes interact more directly and intensively with tropical deep convection than the cold fronts that support the SACZ formation, which usually penetrate very little over tropical SA and stimulate tropical deep convection basically by means of midlatitude cold-air incursions (Siqueira and Machado 2004). This tends to favor the most intense convection observed within the type $1 \mathrm{CS}$.

Figure 6 shows the cumulative distributions of the rain fractions within the CSs during their mature phase (life cycle variability will be discussed later). Rain fractions $>30 \%$ are found within $54 \%-67 \%$ of the tropical CSs, and only $0 \%-5 \%$ of the tropical CSs have no rain present. The type 2 CSs show the largest rain fractions over the Tropics. The convective rain type is also notable within the tropical CS at the mature phase, with only $0 \%-6 \%$ of CSs containing no convective rain and $22 \%-39 \%$ of CSs containing convective rain fractions $>30 \%$, as shown in Fig. 7 (life cycle variability will be discussed later). The largest convective rain fractions over the Tropics are found within the type $1 \mathrm{CS}$. The significant rain and convective rain fractions within the tropical CS confirm the important role played by cold fronts advancing into lower tropical latitudes and the SACZ formation on the frequency of precipitation in the Tropics. Another important point is the relationship between the VIS-DX cloud properties and the PR rain properties at the mature phase of CSs. Rain fractions are directly associated with deep convective cloud fractions within CSs, as also observed in the largely positive correlations between these parameters obtained for all the CS groups and shown in Table 3. Similarly, convective rain fractions are directly proportional to deep convective cloud mean optical thickness, as shown in Table 3 by means of positive correlations between both parameters. The main physical idea is that the CSs containing larger areas occupied by deep convective clouds exhibit larger areas influenced by rain, while the CSs with stronger vertical development of deep convective clouds produce more intense convection and have larger areas affected by convective rain. Hence, the SACZ formation forms CSs with larger fractions of deep convective clouds and larger rain fractions over the Tropics, while the cold fronts that advance into lower tropical latitudes form CS with stronger vertical development of deep convective clouds and larger convective rain fractions.

The mean stratiform rain profile of the tropical CSs 
(a)

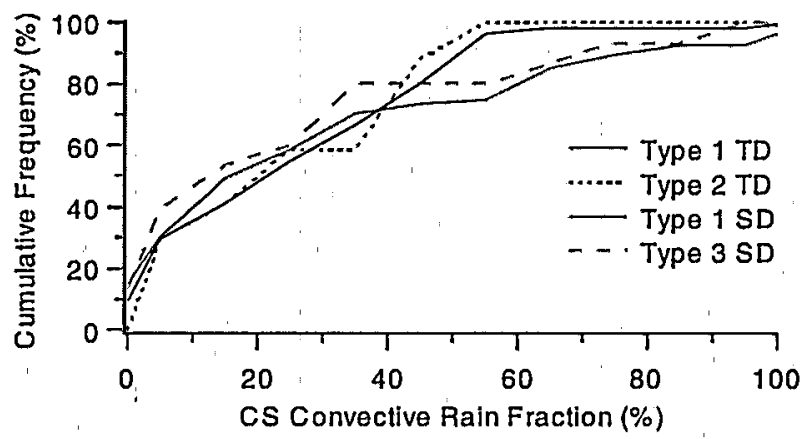

(b)

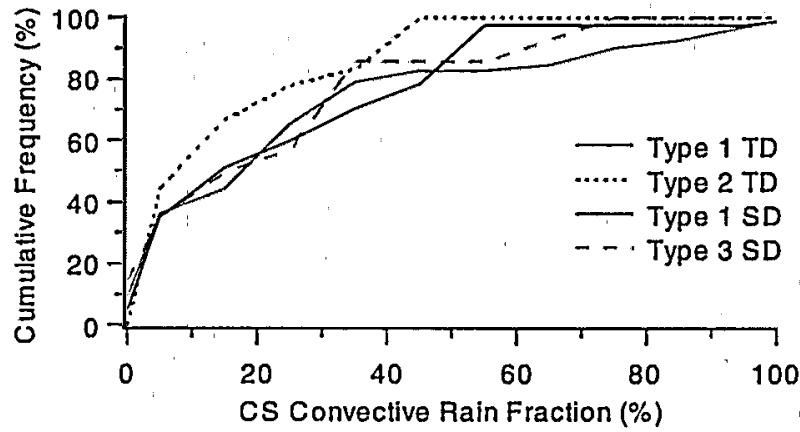

(c)

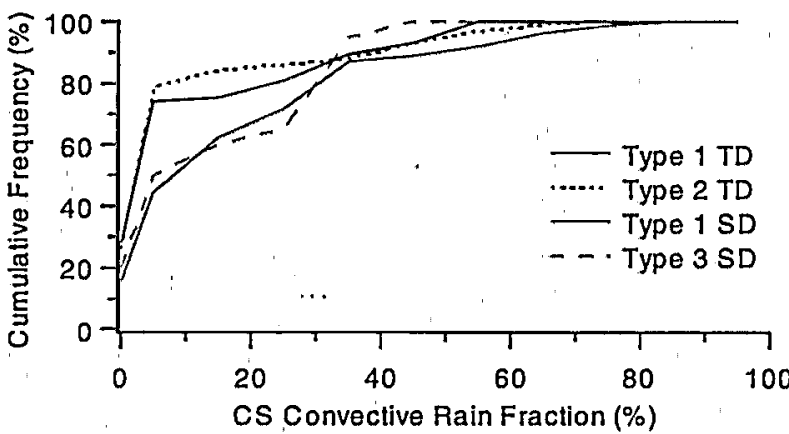

Flg. 7. Cumulative distributions of the CS number vs convective rain fractions at the (a) initiation, (b) maturation, and (c) decay phases of the CS life cycle obtained from collocated TRMM PR pixels for the four CS groups. Statistics are accumulated for fraction ranges of $10 \%$.

during their mature phase consists of rainfall rates between 1.8 and $2 \mathrm{~mm} \mathrm{~h}^{-1}$ at $2 \mathrm{~km}$ and maximum rainfall rates between 2.3 and $2.8 \mathrm{~mm} \mathrm{~h}^{-1}$ at $4-4.3 \mathrm{~km}$, as shown in Fig. 8. Although no substantial differences are found between types 1 and 2 tropical CSs, it is important to note that the slightly larger mean stratiform rainfall rates within the type $1 \mathrm{CS}$ are directly associated with a larger ice amount at higher levels that melts close to the freezing level and characterizes the bright band during the occurrence of stratiform rain type. This may be related to a stronger vertical development of deep con- vective clouds that was found within the type $1 \mathrm{CS}$, which produces colder cloud tops and larger ice amounts at higher levels over the Tropics (Fig. 5). The mean convective rain profile of the tropical CSs during their mature phase is characterized by rainfall rates between 12.3 and $14 \mathrm{~mm} \mathrm{~h}^{-1}$ at $2 \mathrm{~km}$ and maximum rainfall rates between 12 and $14.2 \mathrm{~mm} \mathrm{~h}^{-1}$ at $3-3.8 \mathrm{~km}$ (Fig. $8)$. The type 2 CSs exhibit about $2 \mathrm{~mm} \mathrm{~h}^{-1}$ larger mean convective rainfall rates than type $1 \mathrm{CSs}$ at $2-4 \mathrm{~km}$, and a mean maximum situated around $0.8 \mathrm{~km}$ lower. Despite that, the type $1 \mathrm{CS}$ showed the largest individual

TABLE 3. Most significant linear correlations and variances obtained from TRMM PR $\times$ VIS-DX and TRMM TMI $\times$ TRMM PR variables at the mature phase of the CS life cycle for all CSs containing matched TRMM PR and VIS-DX measurements.

\begin{tabular}{|c|c|c|c|}
\hline Correlation & ' Variables & $\begin{array}{l}\text { Coef of } \\
\text { linear } \\
\text { correlation }\end{array}$ & Variance \\
\hline $\mathrm{PR} \times$ VIS $-\mathrm{DX}$ & $\begin{array}{l}\text { CS rain fraction } \times C S \text { deep convective clouds } \\
\text { fraction }\end{array}$ & +0.70 & $\begin{array}{l}671 \text { (rain fraction); } 763 \text { (deep convective clouds } \\
\text { fraction) }\end{array}$ \\
\hline 1 & $\begin{array}{l}\text { CS convective rain fraction } \times C S \text { deep } \\
\text { convective clouds mean optical thickness }\end{array}$ & +0.32 & $\begin{array}{l}124 \text { (convective rain fraction); } 498 \text { (mean cloud } \\
\text { optical thickness) }\end{array}$ \\
\hline & $\begin{array}{l}\text { CS mean integral of convective rain rate } \times \text { CS } \\
\text { deep convective clouds mean optical thickness }\end{array}$ & +0.48 & $\begin{array}{l}640 \text { (mean integral of convective rain rate); } \\
498 \text { (mean cloud optical thickness) }\end{array}$ \\
\hline \multirow[t]{2}{*}{$\mathrm{TMI} \times \mathrm{PR}$} & $\begin{array}{l}\mathrm{CS} \text { mean brightness temperature at } 85.5 \mathrm{GHz} \\
\times \mathrm{CS} \text { convective rain fraction }\end{array}$ & -0.50 & \multirow{2}{*}{$\begin{array}{l}248 \text { (mean brightness temperature); } \\
124 \text { (convective rain fraction) } \\
93 \text { (deviation of the brightness temperature); } \\
124 \text { (convective rain fraction) }\end{array}$} \\
\hline & $\begin{array}{l}\text { CS mean deviation of the brightness temperature } \\
\text { at } 85.5 \mathrm{GHz} \times \mathrm{CS} \text { convective rain fraction }\end{array}$ & +0.70 & \\
\hline
\end{tabular}


(a)

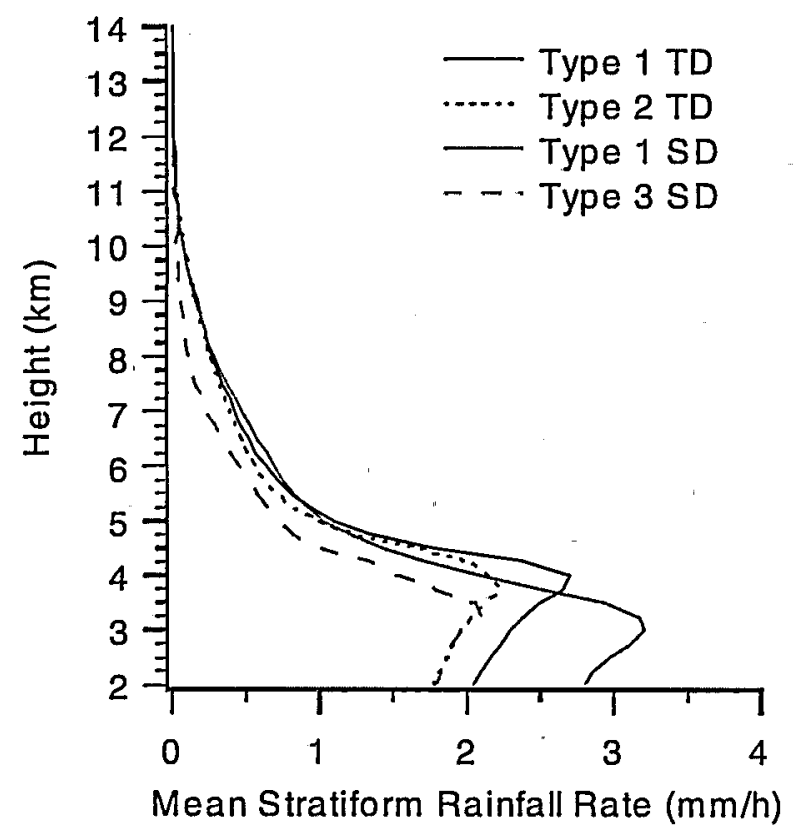

(b)

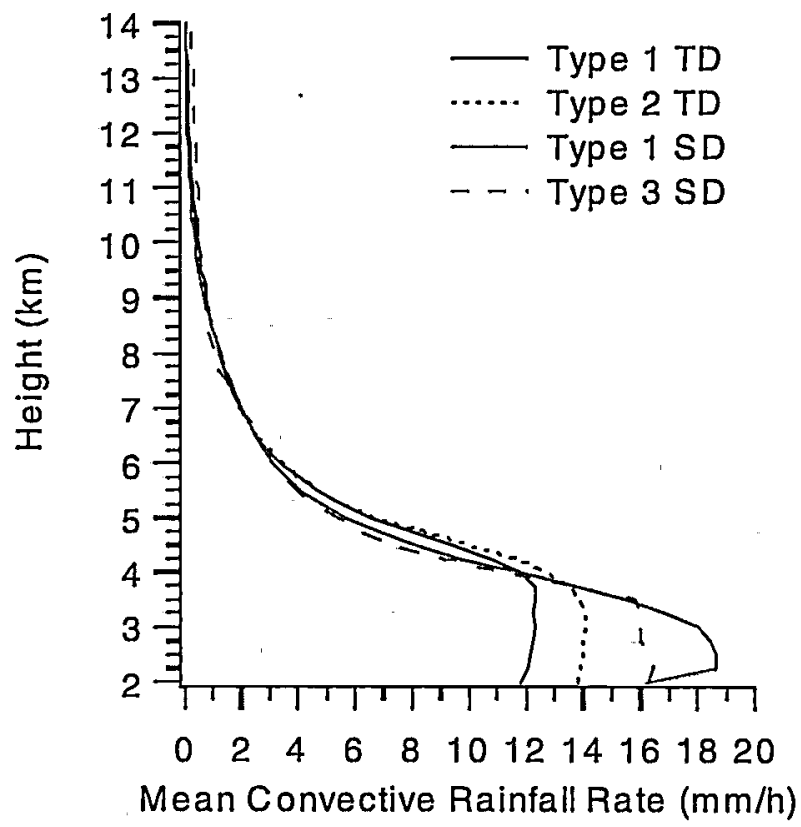

FIG. 8. Mean (a) stratiform and (b) convective rainfall rate profiles for every $0.25 \mathrm{~km}$ (above $2 \mathrm{~km}$ ) estimated from the $2 A 25 / P R$ pixels at the mature phase of the CS life cycle for the four CS groups.

convective rainfall rates (not shown). The preferential heights of maximum rainfall rates located near the freezing level (for stratiform rain) and near or below the freezing level (for convective rain) over the Tropics were also observed by $\mathrm{Fu}$ and $\mathrm{Liu}$ (2001). The large values of mean convective rainfall rate within the tropical CS show that the cold fronts that advance into lower tropical latitudes and the SACZ formation have a pronounced impact on the rainfall regimes in tropical SA during the austral wet season.

We have also investigated possible relationships between the PR convective rainfall rates and the $D X$ cloud properties within all the CS by estimating the mean integral of the convective rainfall rates above 2 $\mathrm{km}$ and linear correlations between this property and the deep convective cloud mean optical thickness for each of the CSs during their mature phase (Table 3). Largely positive correlations were found between both CS properties, suggesting that the largest convective rainfall rates are produced by CSs with stronger vertical development of deep convective clouds. As the type 2 CSs exhibit slightly larger mean convective rainfall rates than the type 1 CSs over the Tropics, we believe that the most extreme static instability conditions within the CSs with a stronger vertical development (type $1 \mathrm{CS}$ ) result in a distribution of less uniform vertical extent of deep convective clouds and convective rainfall rates within the $C S$, making them produce the largest individual values of convective rainfall rate but with mean values sometimes comparable or even slightly smaller with respect to the CS characteristic of a weaker vertical development CS (type 2). This speculation, which is also based on the fact that the convective precipitation regimes are associated with significant turbulence in the clouds and intense variability of both liquid and ice water contents and rainfall rates at low tropospheric levels (Houze 1993), is consistent with the more uniform distribution of deep convective clouds within the CS associated with the SACZ formation over the Tropics discussed previously (Fig. 5). As a result, the tropical CSs produced along the SACZ form with larger fractions of deep convective clouds but with warmer top temperatures than the tropical CSs generated by cold fronts moving into lower tropical latitudes and produce slightly larger (smaller) mean (individual) convective rainfall rates, with maximum values situated at lower levels.

The complementary rainfall description for the four CS groups during their mature phase by TMI microwave brightness temperatures is presented in Fig. 9 in terms of cumulative distributions of the means and mean deviations of brightness temperatures for each of the CSs. Since the occurrence of warm rain or surface contamination in the TMI measurements may be present and does not produce the attenuation necessary in the microwave radiances to indicate rain presence, the fraction of the tropical CSs associated with rain expressed by colder TMI brightness temperatures is not as large as the one estimated from PR measurements. Despite that, the type $1 \mathrm{CSs}$ containing mean brightness temperatures colder than $230 \mathrm{~K}$ [usually characteristic of rain, according to Hong et al. (1999)] and brightness 
(a)

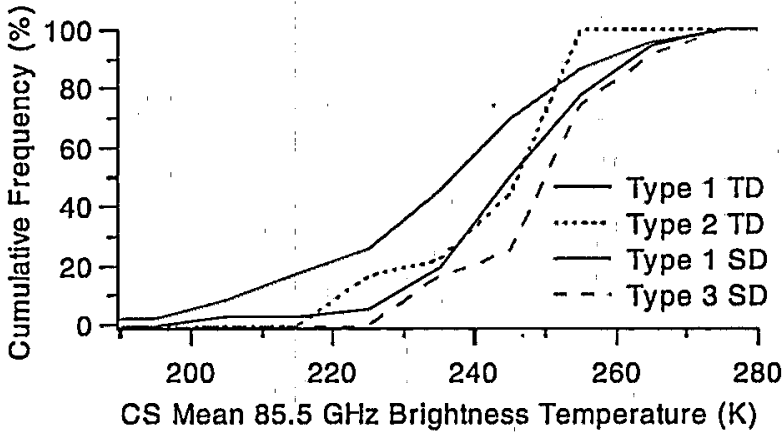

(b)

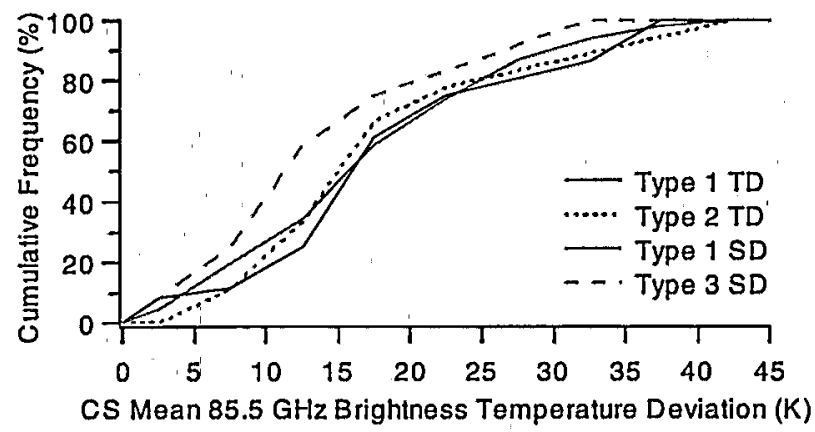

FIG. 9. Cumulative distributions of the CS number described by PR/TMI measurements vs (a) mean and (b) mean deviation of microwave brightness temperatures at $85.5 \mathrm{GHz}$ estimated from the 1B11/TMI pixels at the mature phase of the CS life cycle for the four CS groups. Statistics are accumulated for temperature ranges of $10 \mathrm{~K}$ and temperature deviation ranges of $5 \mathrm{~K}$.

temperature deviations larger than $15 \mathrm{~K}$ are more numerous than type $2 \mathrm{CSs}$, suggesting a strong dependence of the means and mean deviations of brightness temperatures with respect to the convective rain fractions estimated by PR. Significantly negative (positive) linear correlations between the mean brightness temperatures (mean brightness temperature deviations) and the convective rain fractions are shown in Table 3 , confirming this hypothesis. This means that the CSs with stronger vertical development of deep convective clouds contain larger fractions of ice clouds and convective rain in the atmosphere, consequently attenuating and varying more strongly the microwave radiances. Thus, the tropical CSs initiated by cold fronts moving into lower tropical latitudes, with larger ice amounts (colder cloud tops), larger convective rain fractions, and larger individual convective rainfall rates (larger rain intensity) than the tropical CSs initiated along the SACZ formation, seem to cause larger attenuations and variability in the $85.5-\mathrm{GHz}$ microwave brightness temperatures over the Tropics.

\section{b. CS over the subtropics/midlatitudes}

The CS over the subtropics/midlatitudes attain their largest very. high cold cloud fractions more uniformly over the day, exhibiting preferential times of the mature phase in the late afternoon, early evening, and morning (Fig. 3). This is probably caused by a stronger frontal activity over the subtropics/midlatitudes that triggers convective activity several times a day during the passage of cold fronts over that region. These CS are also characterized by lifetimes primarily between 3 and $6 \mathrm{~h}(57 \%-63 \%$ of CS) and effective radii predominantly between 90 and $150 \mathrm{~km}(75 \%-80 \%$ of CS) at their mature phase, with more type $1 \mathrm{CSs}$ containing longer lifetimes and larger effective radii than type 3 CSs, and very high cold cloud fractions $>30 \%$ within about $82 \%$ of the types 1 and 3 CSs (not shown). The effective radius and very high cold cloud distributions produced by the types 1 and 3 events show that the cold fronts moving into lower tropical latitudes (type 1) and the quasi-stationary cold fronts (type 3 ) contribute to the formation of mesoscale CSs over subtropical SA with significant sizes and large fractions of clouds that are frequently associated with deep convection. Among the subtropical CS that last longer than $6 \mathrm{~h}$ and exhibit times of the mature phase in the early morning (less than $30 \%$ of CS) appear the mesoscale convective complexes (MCCs) studied by Velasco and Fritsch (1987). The MCCs are produced east of the Andes by a lowlevel jet (LLJ) and are apparently stimulated by coldfrontal incursions toward southeast SA.

The high cold clouds within the CSs over the subtropics/midlatitudes were observed moving toward lower latitudes (predominantly northeastward) during the type 1 events in $32 \%$ of type 1 subtropical CSs (not shown). However, the type 1 very high cold clouds move toward lower latitudes $10 \%$ more often than the type 1 high cold clouds, suggesting an important role of cold fronts in also moving with deep convection over the subtropics into the Tropics. The type 3 high cold clouds moving toward lower latitudes over the subtropics/midlatitudes are about $13 \%$ less than the type 1 , but the type 3 very high cold clouds moving toward lower latitudes are about $12 \%$ more than the type 3 high cold clouds moving toward lower latitudes (not shown). The type 3 CS direction distributions reveal that the quasistationary cold fronts over the subtropics that have a weaker interaction with tropical convection move much more zonally (predominantly eastward) with deep convection, but may also organize some convective activity toward the Tropics and independent of the propagation direction of the cold front. Similarly to the tropical CS, the convective cloudiness organization in mesoscales by the types 1 and 3 events in the subtropics and midlatitudes is oriented preferentially around the zonal component. The majority of the types 1 and 3 subtropical CSs also move with propagation speeds $<10 \mathrm{~m} \mathrm{~s}^{-1}$, 
consistent with their modulation by frontal incursions (not shown).

The CSs over the subtropics/midlatitudes exhibit significant fractions of thick cirrus clouds during their mature phase, so that $38 \%-62 \%$ of CSs contain cloud fractions $>30 \%$ and the type 3 CSs have the largest cloud fractions (Table 2). Large deep convective cloud fractions are also noted within these CSs at their mature phase, with $62 \%-73 \%$ of CSs containing cloud fractions $>30 \%$ and only $14 \%-22 \%$ of CSs without deep convective clouds (Fig. 4). As the type 1 CSs exhibit the largest deep convective cloud fractions, the cold fronts over the subtropics that advance into lower tropical latitudes are responsible for the largest fractions of deep convective clouds, while the quasi-stationary cold fronts over the subtropics have considerably higher fractions of stratiform clouds. The deep convective clouds within the CSs exhibit minimum cloud-top temperatures predominantly between 192 and $222 \mathrm{~K}$ at their mature phase, with the coldest (top temperatures $<210 \mathrm{~K}$ ) and the thickest (optical thickness $>33$ ) deep convective clouds being found within the type $1 \mathrm{CS}$ (Fig. 5). The distributions of deep convective cloud fractions and deep convective cloud minimum top temperature and optical thickness within these CSs show that the cold fronts moving into lower tropical latitudes produce CSs with larger fractions and stronger vertical development of deep convective clouds than the CSs initiated by quasi-stationary cold fronts in the subtropics. As the cold fronts moving into lower tropical latitudes are accompanied by more intense midlatitude cold-air incursions into the Tropics (Siqueira and Machado 2004), they tend to interact more strongly with the tropical wet, hot air masses and stimulate deep convection over larger areas and with more vertical development over subtropical SA than the quasistationary cold fronts.

The CSs over the subtropics/midlatitudes are also associated with significant rain fractions during their mature phase (Fig. 6). Only $7 \%-12 \%$ of CSs have no rain present but $28 \%-65 \%$ of CSs contain rain fractions $>30 \%$, with the largest fractions being found within the type $1 \mathrm{CS}$. The rain distributions confirm a significant rain presence within the types 1 and 3 CSs and also show a direct relationship with respect to the distributions of deep convective cloud fractions within the types 1 and 3 CSs over the subtropics/midlatitudes (Fig. 4 and Table 3 ). Only $10 \%-15 \%$ of CSs contain no convective rain during their mature phase, while $29 \%-38 \%$ of CSs have convective rain fractions $>30 \%$ (Fig. 7 ). Despite the fact that the type $3 \mathrm{CSs}$ with convective rain fractions $>30 \%$ are more numerous ( $+9 \%$ of CSs), the type 1 CSs with convective rain fractions $>70 \%$ are more numerous $(+8 \%)$ and correspond directly to the CSs containing the thickest deep convective clouds over the subtropics/midlatitudes (Fig. 5 and Table 3). Thus, the cold fronts that move into lower tropical latitudes initiate CSs over the subtropics with larger fractions of deep convective clouds and rain, as well as stronger vertical development of deep convective clouds and larger convective rain fractions compared to the CS initiated by quasi-stationary cold fronts over the subtropics.

The mean stratiform rain profile of the CS over the subtropics/midlatitudes is characterized by rainfall rates around $1.8-2.8 \mathrm{~mm} \mathrm{~h}^{-1}$ at $2 \mathrm{~km}$ and maximum rainfall rates around $2.3-3.3 \mathrm{~mm} \mathrm{~h}^{-1}$ near the freezing level $(3.3$ $\mathrm{km}$ ) during their mature phase (Fig. 8). The differences between the stratiform rainfall rates of the types 1 and $3 \mathrm{CSs}$ are not so significant $\left(<1 \mathrm{~mm} \mathrm{~h}^{-1}\right)$, but are larger than the tropical CSs. Similarly to the Tropics, the larger mean stratiform rainfall rates in the subtropics/ midlatitudes are found within the type 1 CSs and may be related to a larger ice amount at higher levels that melts close to the freezing level within the type $1 \mathrm{CS}$. Hence, the stronger vertical development of deep convective clouds within the type $1 \mathrm{CS}$ tends to produce colder cloud tops and larger ice amounts at higher levels in the subtropics and midlatitudes (Fig. 5). The mean convective rain profile of the CS over the subtropics/midlatitudes during their mature phase is represented by rainfall rates around $16 \mathrm{~mm} \mathrm{~h}^{-1}$ at $2 \mathrm{~km}$ and maximum rainfall rates around $16-18 \mathrm{~mm} \mathrm{~h}^{-1}$ below the freezing level, both at about $2.5 \mathrm{~km}$ (Fig. 8). The type $1 \mathrm{CSs}$ exhibit around $2 \mathrm{~mm} \mathrm{~h}^{-1}$ larger mean convective rainfall rates than the type 3 CSs below 4 $\mathrm{km}$. The largest individual convective rainfall rates were also exhibited by the type 1 CS (not shown). The significant mean convective rainfall rates found within the types 1 and 3 CSs indicate the importance of the cold fronts that advance into lower tropical latitudes or remain quasi-stationary over the subtropics on the precipitation regime in subtropical SA during the austral wet season. Similarly to the tropical CSs, the largest individual convective rainfall rates within the CSs over the subtropics/midlatitudes are directly related to the vertical development of their deep convective clouds (deep convective cloud mean optical thickness), as shown in Fig. 5 and Table 3. The CSs initiated by the cold fronts moving into lower tropical latitudes, with larger fractions and stronger vertical development of deep convective clouds than the CSs initiated by quasistationary cold fronts in the subtropics, produce not only the largest individual but also the largest mean convective rainfall rates over the subtropics and midlatitudes.

The two distributions of $85.5-\mathrm{GHz}$ brightness temperatures for the CSs in the subtropics/midlatitudes during their mature phase show a larger type $1 \mathrm{CS}$ number with mean temperatures colder than $220 \mathrm{~K}$ and mean temperature deviations $>30 \mathrm{~K}$ with respect to the type 3 CS (Fig. 9). Both distributions testify to the relationships between the brightness temperatures and the convective rain fractions within the CSs observed previously for the tropical CSs (Fig. 5 and Table 3). As a result, the CSs initiated by cold fronts that advance 
into lower tropical latitudes apparently cause more attenuation and variation in the $85.5-\mathrm{GHz}$ brightness temperatures than the quasi-stationary cold fronts over the subtropics probably due to their larger ice amounts in the atmosphere (colder cloud tops), larger convective rain fractions, and larger convective rainfall rates (rain intensity).

\section{c. Tropical CS versus CS over the subtropics/midlatitudes}

As discussed in previous sections, cold fronts over tropical SA and cold fronts over the subtropics/ midlatitudes have different behaviors. The summary of the most important differences in the CS structure between these two geographical regions is presented for the tropical type 1 CSs and type 1 CSs over the subtropics/midlatitudes. The majority of the tropical CSs initiated by cold fronts over the Tropics attain their largest very high cold cloud fraction in the late afternoon and early evening, while the CS initiated by cold fronts over the subtropics/midlatitudes attain their largest very high cold cloud fraction more uniformly distributed over the day. That is probably due to a stronger frontal activity that stimulates convection more frequently during the day over the subtropics (Fig. 3). The CSs initiated by cold fronts over the subtropics/ midlatitudes exhibit larger lifetimes and effective radii, with about $18 \%$ fewer (more) CSs having 3-6-h (9-24 h) lifetimes and $11 \%$ more CSs with effective radii between 120 and $270 \mathrm{~km}$ than the tropical CSs initiated by cold fronts over the Tropics. Similar differences in effective radius and lifetime distributions between CSs over the Tropics and the midlatitudes were observed by Velasco and Fritsch (1987) and related to a stronger frontal activity favored by intense baroclinic instability over the midlatitudes. As $9 \%$ (13\%) more CSs with high cold (very high cold) clouds moving toward lower latitudes with cold fronts over the subtropics are found with respect to the tropical CSs, the strongest frontal activity in the subtropics and midlatitudes is responsible for the most frequent propagations of deep convection with the cold fronts toward the equator over the subtropics than over the Tropics (not shown).

The CSs over the subtropics/midlatitudes also show significantly larger fractions of deep convective clouds than the tropical CSs, with $25 \%$ more CSs having cloud fractions $>70 \%$ (Fig. 4). However, the deep convective clouds within the tropical CSs have significantly colder tops and are optically thicker (Fig. 5). The distributions of rain and convective rain fractions within the CSs are also related to the deep convective cloud fractions and their minimum cloud-top temperatures (Figs. 6 and 7), respectively, such that the CSs over the subtropics/ midlatitudes exhibit the largest rain fractions (11\% more CSs with rain fractions $>30 \%$ ) but the tropical CSs have the largest convective rain fractions ( $10 \%$ more CSs with fractions $>30 \%$ ). The CSs over the subtropics/midlatitudes exhibit mean maximum convective rainfall rates about $6 \mathrm{~mm} \mathrm{~h}^{-1}$ larger and at around $1.3-\mathrm{km}$ lower level with respect to the tropical CSs (Fig. 8), while the tropical CSs with individual maximum convective rainfall rates $>40 \mathrm{~mm} \mathrm{~h}^{-1}$ are more numerous (not shown). These convective rainfall rate differences were also confirmed in the PR mean reflectivity profiles built for convective rain type (not shown). The largest fractions of deep convective clouds and rain added to the distributions of warmer deep convective cloud-top temperatures and smaller convective rain fractions within the CSs initiated by cold fronts over the subtropics/midlatitudes show that the cold fronts penetrating over subtropical SA organize convective activity over larger areas and more uniformly over the subtropics due to their usual intensification by baroclinic processes over that region. On the other hand, the most intense convection episodes observed within the tropical CSs initiated by cold fronts over tropical SA (colder cloud tops, larger convective rain fractions) are favored by a larger availability and a larger vertical distribution of water vapor in the tropical troposphere, which contributes to form CS with larger individual convective rainfall rates in the Tropics.

\section{Main aspects of life cycle variability of CS cloud and rainfall properties}

The composite evolution of some CS cloud and rain properties during their life cycle is presented for the tropical CSs (types 1 and 2) and the CSs over the subtropics/midlatitudes (types 1 and 3 ). Despite $29 \%-41 \%$ of the CSs with collocated VIS-DX and TRMM PR measurements available showing coincident times of the initiation and mature phases and $6 \%-14 \%$ having coincident times of the mature and decay phases, life cycle variations could be observed (Figs. 4, 6, and 7). The evolution of the CS cloud and rain properties over a life cycle reveals a more intense initial development in the fractions of deep convective clouds, rain fractions, and convective rain fractions within the tropical CSs than in the CSs over the subtropics/midlatitudes, with values predominantly larger or comparable to those at the mature phase and characterizing tropical CSs as the most explosive (rapidly growing). The CSs over the subtropics/midlatitudes exhibit a slower decay in convective activity over a life cycle, probably associated with support from stronger frontal activity in the subtropics. The CSs initiated along the SACZ formation (type 2) appear more explosive over the Tropics, exhibiting longer lifetimes of deep convective clouds and rain, probably associated with the larger scale and more uniform organization of convective activity by the SACZ over the Tropics. However, the CSs produced by cold fronts that move into lower tropical latitudes (type 1) have a much slower decay in convective rain over the Tropics during a life cycle, showing that cold fronts stimulate more intense convection longer over the 
(a)

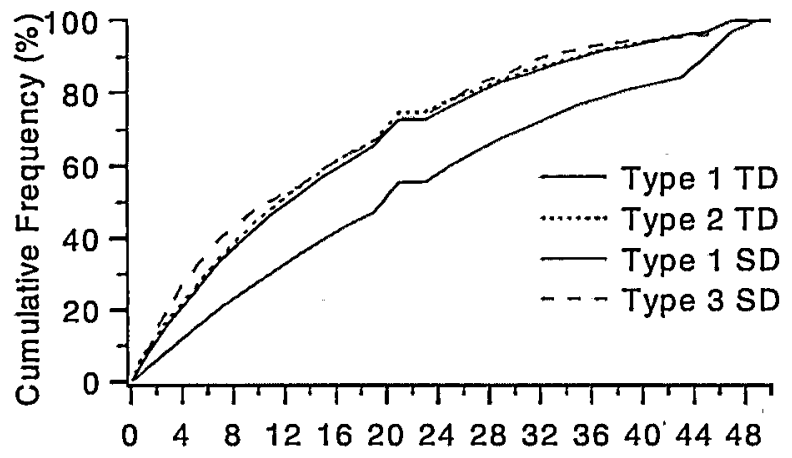

CS Maximum Convective Rainfall Rate $(\mathrm{mm} / \mathrm{h})$ (b)

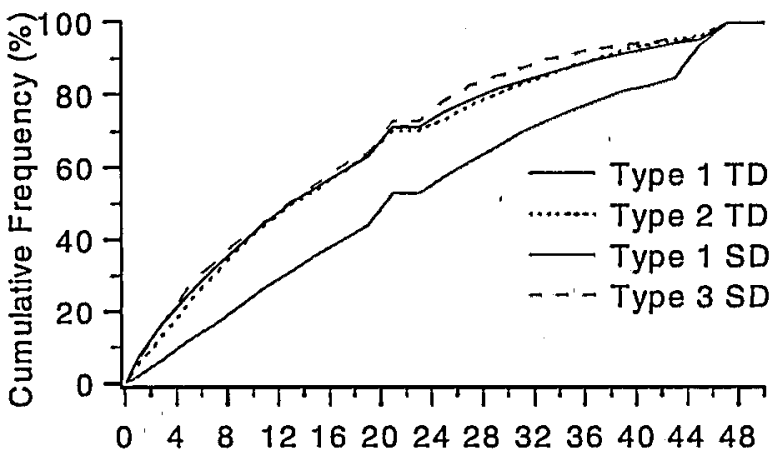

CS Maximum Convective Rainfall Rate $(\mathrm{mm} / \mathrm{h})$

(c)

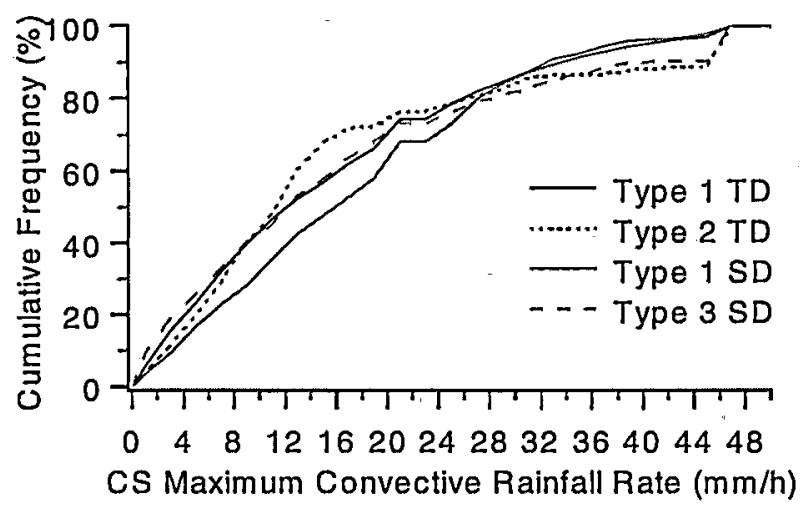

FIG. 10. Cumulative distributions of the number of $C S$ convective raining $P R$ pixels vs maximum convective rainfall rate estimated from 2A25 and 2A23/PR pixels at the (a) initiation, (b) maturation, and (c) decay phases of the CS life cycle for the four CS groups. Statistics are accumulated for rainfall rate ranges of $2 \mathrm{~mm} \mathrm{~h}^{-1}$.

Tropics, probably because of their more direct interaction with tropical deep convection. The CSs initiated by cold fronts that advance into lower tropical latitudes are more explosive and exhibit a longer lifetime of deep convective clouds and rain over the subtropics/ midlatitudes, which is apparently favored by more intense midlatitude cold-air incursions into the Tropics. Although the CSs produced by quasi-stationary cold fronts in the subtropics (type 3 ) have a slower decay of convective rain over a life cycle, probably because of these fronts' persistence, this is not significant because of a drastic fall in their rain fractions during a life cycle.

Since large differences in the CS mean rainfall rate profiles were found for convective rain type at their mature phase (Fig. 8), we have also investigated the evolution of the maximum convective rainfall rates during the CS life cycle in terms of cumulative distributionis, as shown in Fig. 10. The tropical CSs and the type 3 CSswover the subtropics/midlatitudes exhibit maximum convective rainfall rates concentrated between 2 and $12 \mathrm{~mm} \mathrm{~h}^{-1}$, while the type $1 \mathrm{CSs}$ over the subtropics/midlatitudes have a broader distribution of maximum convective rainfall rates between 2 and 40 $\mathrm{mm} \mathrm{h}^{-1}$. The tropical type 2 CSs contain a similar distribution of maximum convective rainfall rates as the tropical type 1 CSs at initiation phase but with slightly higher rainfall rates at the mature phase, as observed in the mean profiles (Fig. 8). However, the tropical type 2 CSs exhibit significantly lower maximum convective rainfall rates at the decay phase. This shows that the tropical CSs initiated along the SACZ formation, observed to be more explosive, have a distribution of slightly larger maximum convective rainfall rates at their mature phase with respect to the tropical CSs produced by cold fronts that move into lower tropical latitudes, but decline more quickly over the life cycle. That is probably due to more capability of the cold fronts that advance into lower tropical latitudes to stimulate intense convection longer over the Tropics, as discussed previously. Over the subtropics/midlatitudes, the type 1 CSs have larger maximum convective rainfall rates than type 3 CSs during the life cycle, consistent with the mean profiles at the mature phase (Fig. 8). Thus, larger maximum convective rainfall rates occur within the CSs 
produced by cold fronts that move into lower tropical latitudes and are characterized by more intense midlatitude cold-air incursions into the Tropics, as discussed previously.

\section{Summary and conclusions}

Data from ISCCP DX and microwave active and passive sensors collected by the TRMM satellite were used to identify and describe the structural characteristics of CS over SA related to cold-frontal incursions and their interaction with tropical convection in a 3-yr period. An austral wet-season climatology for CS events of the three most important types of fronttropical convection interaction is built by applying latitude-time diagrams and a cloud-tracking method to DX data. Type 1 is characterized by the penetration of a cold front over subtropical SA that interacts with tropical convection and moves with it into lower tropical latitudes. Type 2 refers to deep convection in the Amazon basin and its enhancement in a quasistationary northwest-southeast-oriented band extending from the Amazon to subtropical SA and stimulated by the passage of a cold front in the subtropics, which characterizes the synoptic formation of the SACZ. A quasi-stationary cold front over subtropical SA that has only weak interaction with tropical convection corresponds to type 3 .

A structural description of the CS associated with the three types of front-tropical convection interaction was performed by using CS cloud properties provided by DX data and CS rainfall estimates from the TRMM PR and TRMM TMI microwave sensors. The statistical distributions of the CS types over continental SA show that type 1 modulates deep convection over almost the whole SA, while types 2 and 3 have more impact on deep convection over tropical and subtropical SA, respectively. The three types of events strongly modulate deep convection by originating a large number of mesoscale CSs moving predominantly around the zonal component, with effective radii up to $270 \mathrm{~km}$ (preferentially of 90-150 km), dominant subdiurnal lifetimes (preferentially of 3-6 h), and large fractions of cirrostratus and deep convective clouds at the CS mature phase. The large convective rain fractions and the mean maximum convective rainfall rates of $12-19 \mathrm{~mm} \mathrm{~h}^{-1}$ at the mature phase confirm the impact of the three types of events on the precipitation regime in SA during the wet season.

The tropical CS initiated by cold fronts that advance into lower tropical latitudes (type 1) and along the SACZ formation (type 2) exhibit their largest fractions of very high cold clouds in the late afternoon and early evening, consistent with a diurnal cycle of deep convection often observed over tropical land areas. A significant amount of very high cold clouds is observed within CSs moving toward lower latitudes (primarily toward northeast SA with cold fronts and secondarily toward central SA and the Amazon basin with midlatitude cold-air incursions) as part of type 1 events and toward higher latitudes (without preferential direction) as part of type 2 events. This association suggests an important role of the cold fronts moving into lower tropical latitudes and the mechanisms of the SACZ formation in organizing tropical deep convection toward lower and higher tropical latitudes, respectively. The quasistationary convective cloudiness organization over tropical SA by the SACZ mechanisms tends to stimulate deep convection over larger areas and to establish more uniform distribution of deep convective clouds with fewer intense convection episodes over the Tropics, resulting in CSs with larger fractions of deep convective clouds and rain, and producing slightly larger mean convective rainfall rates in the Tropics at their mature phase. On the other hand, the cold fronts that move into lower tropical latitudes interact more directly and intensively with tropical convection than the cold fronts that support the SACZ formation, which usually penetrate very little over tropical SA and stimulate tropical convection, especially by means of midlatitude cold-air incursions. This tends to favor the most intense convection and initiates CS with stronger vertical development of deep convective clouds (colder and thicker clouds), larger convective rain fractions, and producing larger individual convective rainfall rates in the Tropics at their mature phase.

The CSs over the subtropics/midlatitudes related to cold fronts that move into lower tropical latitudes (type 1) and quasi-stationary cold fronts in the subtropics (type 3) exhibit less of a diurnal cycle with maximum very high cold cloud fractions distributed more uniformly over the day, apparently caused by stronger frontal activity that triggers convective activity over the day. A significant amount of very high cold clouds moving northeastward is found within the type 3 CSs and preferentially within the type $1 \mathrm{CSs}$, showing the importance of the cold fronts, and especially the cold fronts that move into lower tropical latitudes in organizing deepiconvection toward tropical SA over the subtropics and midlatitudes. As the cold fronts moving into lower tropical latitudes are characterized by more intense midlatitude cold-air incursions into the Tropics than the quasi-stationary cold fronts, they tend to interact more strongly with the tropical wet, hot air masses and stimulate deep convection over larger areas and more intensively over subtropical SA. This favors not only the formation of CSs with larger fractions of deep convective clouds and rain over the subtropics and midlatitudes, but also the formation of CS with stronger vertical development of deep convective clouds, larger convective rain fractions, and producing larger mean and individual convective rainfall rates during their mature phase.

Important differences in the CS cloud and rain properties at their mature phase were also observed by comparing the tropical type $1 \mathrm{CS}$ with the type $1 \mathrm{CS}$ over 
the subtropics/midlatitudes, showing that deep convection stimulated by the cold fronts over tropical and subtropical SA has different structural characteristics. The cold fronts on penetrating over SA organize convection over larger areas and more uniformly in the subtropics, where they are usually intensified by baroclinic processes, forming CSs with larger effective radii, longer lifetimes, larger deep convective cloud fractions, larger rain fractions, and producing larger mean convective rainfall rates. On the other hand, the most intense convection episodes occur when cold fronts interact with convection over tropical SA, which is a region of larger availability and a larger vertical distribution of water vapor in the troposphere, forming CS with stronger vertical development of deep convective clouds, larger convective rain fractions, and producing the largest individual convective rainfall rates.

The evolution of the CS cloud and rain properties during the CS life cycle revealed a more intense initial development in the convective activity (deep convective cloud fractions and rain fractions) and intense convection (convective rain fractions) within the tropical CSs (types 1 and 2) than the CSs over the subtropics/ midlatitudes (types 1 and 3 ). The CSs over the subtropics/midlatitudes exhibit a slower decay in convective activity over a life cycle, probably associated with stronger support of the cold fronts in the subtropics. The cold fronts that move into lower tropical latitudes seem to be important in maintaining the most intense convection episodes longer over the Tropics, while the quasi-stationary convective cloudiness organization by the SACZ mechanisms establishes more uniform and most intense initial development of convective activity over the Tropics. The cold fronts that move into lower tropical latitudes establish a more intense initial development and longer lifetime of convective activity in the subtropics/midlatitudes than the quasi-stationary cold fronts, apparently favored by their more intense midlatitude cold-air incursions into the Tropics. The initial development of the convective activity within the tropical and subtropical CSs is also directly associated to their lifetimes and radii, similar to what was observed by Morales et al. (2002). This may suggest important advances in severe weather forecasts over SA involving cold-frontal incursions.

The use of the ISCCP DX and TRMM PR and TRMM TMI data, together, allowed us to examine a wide variety of structural descriptions of CSs over SA related to cold-frontal incursions, which may be very useful for the mesoscale numeric weather forecast models and for understanding the ability of cold fronts in organizing deep convection and precipitation regime over SA. Since the TRMM sensors do not have the same high time resolution as the ISCCP DX, a combi- nation of these sensors is expected to provide a more comprehensive climatology that permits complementing the structural characteristics of all CS populations tracked on the DX data by the powerful three- dimensional rain description provided by the TRMM sensors in the future.

Acknowledgments. The present work was conducted while the first author was pursuing a Ph.D. degree at INPE under scholarship of the CNPq (Conselho Nacional de Desenvolvimento Cientifico e Tecnologico, Brazil). This study was supported by CNPq Project Grant 474210/01-4. One of us (J.R.S.) acknowledges the good reception during the visit to NASA Goddard Institute for Space Studies, support for which was provided by the NASA TRMM project.

\section{REFERENCES}

Awaka, J., T. Iguchi, and K. Okamoto, 1998: Early results on rain type classification by the Tropical Rainfall Measuring Mission (TRMM) precipitation radar. Preprints, Eighth URSI Commission F Open Symp., Averiro, Portugal, Amer. Meteor. Soc., 134-146.

Bellerby, T., M. Todd, D. Kniveton, and C. Kidd, 2000: Rainfall estimation from a combination of TRMM precipitation radar and GOES multispectral satellite imagery through the use of an artificial network. J. Appl. Meteor, 39, 2115-2128.

Byers, H. R., and R. R. Braham, 1949: The Thunderstorms. U.S. Government Printing Office, $287 \mathrm{pp}$.

Fu, Y., and G. Liu, 2001: The variability of tropical precipitation profiles and its impact on microwave brightness temperatures as inferred from TRMM data. J. Appl. Meteor, 40, 21302143.

Garreaud, R. D., and J. M. Wallace, 1997: The diurnal march of convective cloudiness over the Americas. Mon. Wea. Rev., $125,3157-3171$.

Hong, Y., C. D. Kummerow, and W. S. Olson, 1999: Separation of convective and stratiform precipitation using microwave brightness temperature. J. Appl. Meteor., 38, 1195-1212.

Hlouze, R. A., 1977: Structure and dynamics of a tropical squallline system. Mon. Wea. Rev., 105, 1540-1567.

- 1989: Observed structure of mesoscale convective systems and implications for large-scale heating. Quart. J. Roy. Meteor. Soc., 115, 425-461. 1993: Cloud Dynamics. Academic Press, 573 pp.

Iguchi, T., T. Kozu, R. Meneghini, J. Awaka, and K. Okamoto, 2000: Rain profiling algorithm for the TRMM precipitation radar. J. Appl. Meteor., 39, 2038-2052.

Kalnay, E., and Coauthors, 1996: The NCEP/NCAR 40-Year Reanalysis Project. Bull. Amer. Meteor. Soc., 77, 437-471.

Leary, C. A., and R. A. Houze, 1979: The structure and evolution of convection in a tropical cloud cluster. J. Atmos. Sci., 36, $437-457$.

Machado, L. A. T., and W. B. Rossow, 1993: Structural characteristics and radiative properties of tropical cloud clusters. Mon. Wea. Rev., 121, 3234-3260.

$\longrightarrow, \longrightarrow$, R. L. Guedes, and A. W. Walker, 1998: Life cycle variations of mesoscale convective systems over the Americas. Mon. Wea. Rev., 126, 1630-1654.

Maddox, R. A., 1983: Large-scale meteorological conditions associated with midlatitude, mesoscale convective complexes. Mon. Wea. Rev., 111, 1475-1493.

Meneghini, R., J. A. Jones, T. Iguchi, K. Okamoto, and J. Kwiatkowski, 2001: Statistical methods of estimating average rainfall over large space-timescales using data from the TRMM precipitation radar. J. Appl. Meteor., 40, 568-585.

Morales, C., L. A. T. Machado, and H. Laurent, 2002: Preliminary results of 3D rainfall structure characteristics of the MCS observed in the Amazon during the LBA field campaign. Preprints, 12th Congresso Brasileiro de Meteorologia, Foz do 
'Iguaçu, Brazil, Sociedade Brasileira de Meteorologia, 32873305 .

Nesbitt, S. W., E. J. Zipser, and D. J. Cecil, 2000: A census of precipitation features in the Tropics using TRMM: Radar, ice scattering, and lightning observations. J. Climate, 13, 40874106.

Rossow, W. B., and R. A. Schiffer, 1991: ISCCP cloud data products. Bull. Amer. Meteor. Soc., 72, 2-20.

$\longrightarrow$ and -1999 : Advances in understanding clouds from ISCCP. Bull. Amer. Meteor. Soc., 80, 2261-2288.

Scorer, R., 1977: Clouds of the World. Lothian, $176 \mathrm{pp}$.

Siqueira, J. R., and L. A. T. Machado, 2004: Influence of the frontal systems on the day-to-day convection variability over South America. J. Climate, 17, 1754-1766.

Tao, W.-K., and J. Simpson, 1989: Modeling study of a tropical squall-type convective line. J. Atmos. Sci., 46, 177-201.
C.-H. Sui, B. Ferrier, S. Lang, J. Scala, M.-D. Chou, and K. Pickering, 1993: Heating, moisture, and water budgets of tropical and midlatitude squall lines: Comparisons and sensitivity to longwave radiation. J. Atmos. Sci., 50, 673690.

Thurai, M., and T. Iguchi, 2000: Rain height information from TRMM precipitation radar. Electron. Lett., 36, 1059-1061.

Tollerud, E. I., and S. K. Esbensen, 1985: A composite life cycle of nonsquall mesoscale convective systems over the tropical ocean. Part I: Kinematic fields. J. Atmos. Sci., 42, 823-838.

Velasco, I., and J. M. Fritsch, 1987: Mesoscale convective complexes in the Americas. J. Geophys. Res., 92, 9591-9613.

Zipser, E. J., 1977: Mesoscale and convective-scale downdrafts as distinct components of squall-line structure. Mon. Wea. Rev., 105, $1568-1589$. 


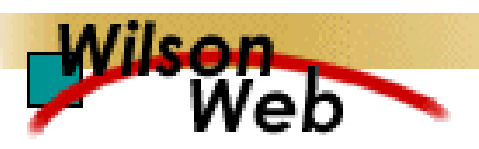

\section{COPYRIGHT INFORMATION}

TITLE: Structural Characteristics of Convective Systems over South America Related to Cold-Frontal Incursions

SOURCE: Mon Weather Rev 133 no5 My 2005

WN: 0512101615001

The magazine publisher is the copyright holder of this article and it is reproduced with permission. Further reproduction of this article in violation of the copyright is prohibited. To contact the publisher: http://www.ametsoc.org/AMS/

Copyright 1982-2005 The H.W. Wilson Company. All rights reserved. 